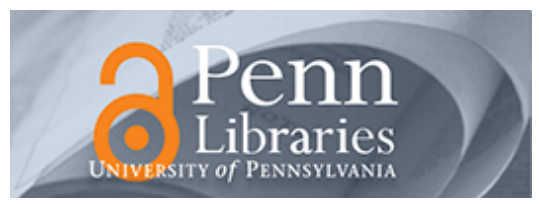

University of Pennsylvania ScholarlyCommons

October 2007

\title{
Structural Changes in the Cervical Facet Capsular Ligament: Potential Contributions to Pain Following Subfailure Loading
}

Kyle P. Quinn

University of Pennsylvania

Kathryn E. Lee

University of Pennsylvania

Chukwunyere C. Ahaghotu

University of Pennsylvania

Beth A. Winkelstein

University of Pennsylvania, winkelst@seas.upenn.edu

Follow this and additional works at: https://repository.upenn.edu/be_papers

\section{Recommended Citation}

Quinn, K. P., Lee, K. E., Ahaghotu, C. C., \& Winkelstein, B. A. (2007). Structural Changes in the Cervical Facet Capsular Ligament: Potential Contributions to Pain Following Subfailure Loading. Retrieved from https://repository.upenn.edu/be_papers/105

Postprint version. Published in Stapp Car Crash Journal, Volume 51, October 2007, pages 169-87.

Publisher URL: http://www.sae.org/technical/books/P-401

This paper is posted at ScholarlyCommons. https://repository.upenn.edu/be_papers/105

For more information, please contact repository@pobox.upenn.edu. 


\title{
Structural Changes in the Cervical Facet Capsular Ligament: Potential Contributions to Pain Following Subfailure Loading
}

\author{
Abstract \\ While studies have demonstrated the cervical facet capsule is at risk for tensile injury during whiplash, the \\ relationship between joint loading, changes in the capsule's structure, and pain is not yet fully \\ characterized. Complementary approaches were employed to investigate the capsule's structure-function \\ relationship in the context of painful joint loading. Isolated $\mathrm{C} 6 / \mathrm{C} 7$ facet joints $(n=8)$ underwent tensile \\ mechanical loading, and measures of structural modification were compared for two distraction \\ magnitudes: $300 \mu \mathrm{m}(\mathrm{PV})$ and $700 \mu \mathrm{m}(\mathrm{SV})$. In a matched in vivo study, C6/C7 facet joints $(\mathrm{n}=4)$ were \\ harvested after the same SV distraction and the tissue was sectioned to analyze collagen fiber \\ organization using polarized light microscopy. Laxity following SV distraction (7.30 $\pm 3.01 \%)$ was \\ significantly greater $(p<0.001)$ than that produced following PV distraction $(0.99 \pm 0.44 \%)$. Also, SV \\ distractions produced significantly higher maximum principal strain $(p<0.001)$ in the capsule and resulted \\ in significantly greater decreases in stiffness $(p=0.002)$ when compared to PV distraction. After SV \\ distraction in vivo, mean angular deviation of the fiber direction $\left(16.8 \pm 2.6^{\circ}\right)$ was significantly increased \\ $(p=0.004)$ relative to naive samples in the lateral region of the capsule, indicating collagen fiber \\ disorganization. These findings demonstrate that certain subfailure loading conditions are associated \\ with altered joint mechanics and collagen fiber disorganization and imply ligament damage. Substructural \\ damage in the capsule has the potential to both directly modulate nerve fiber signaling and produce \\ sustained physiologic modifications that may initiate persistent pain.
}

\section{Keywords}

facet joint; capsular ligament, subfailure, laxity, strain, polarized light; fiber orientation

\section{Comments}

Postprint version. Published in Stapp Car Crash Journal, Volume 51, October 2007, pages 169-87. Publisher URL: http://www.sae.org/technical/books/P-401 
Stapp Car Crash Journal, Vol. 51 (October 2007), pp.

Copyright (C) 2007 The Stapp Association

\title{
Structural Changes in the Cervical Facet Capsular Ligament: Potential Contributions to Pain Following Subfailure Loading
}

\author{
Kyle P. Quinn, Kathryn E. Lee, Chukwunyere C. Ahaghotu, and Beth A. Winkelstein \\ Spine Pain Research Lab \\ Departments of Bioengineering \& Neurosurgery \\ University of Pennsylvania
}

\begin{abstract}
While studies have demonstrated the cervical facet capsule is at risk for tensile injury during whiplash, the relationship between joint loading, changes in the capsule's structure, and pain is not yet fully characterized. Complementary approaches were employed to investigate the capsule's structure-function relationship in the context of painful joint loading. Isolated $\mathrm{C} 6 / \mathrm{C} 7$ facet joints $(\mathrm{n}=8)$ underwent tensile mechanical loading, and measures of structural modification were compared for two distraction magnitudes: $300 \mu \mathrm{m}(\mathrm{PV})$ and $700 \mu \mathrm{m}(\mathrm{SV})$. In a matched in vivo study, C6/C7 facet joints ( $\mathrm{n}=4$ ) were harvested after the same SV distraction and the tissue was sectioned to analyze collagen fiber organization using polarized light microscopy. Laxity following SV distraction $(7.30 \pm 3.01 \%)$ was significantly greater $(p<0.001)$ than that produced following PV distraction $(0.99 \pm 0.44 \%)$. Also, SV distractions produced significantly higher maximum principal strain $(\mathrm{p}<0.001)$ in the capsule and resulted in significantly greater decreases in stiffness $(\mathrm{p}=0.002)$ when compared to PV distraction. After SV distraction in vivo, mean angular deviation of the fiber direction $\left(16.8 \pm 2.6^{\circ}\right)$ was significantly increased $(p=0.004)$ relative to naive samples in the lateral region of the capsule, indicating collagen fiber disorganization. These findings demonstrate that certain subfailure loading conditions are associated with altered joint mechanics and collagen fiber disorganization and imply ligament damage. Substructural damage in the capsule has the potential to both directly modulate nerve fiber signaling and produce sustained physiologic modifications that may initiate persistent pain.
\end{abstract}

KEYWORDS - Facet Joint; Capsular Ligament; Subfailure; Laxity; Strain; Polarized Light; Fiber Orientation

\section{INTRODUCTION}

Chronic neck pain is a tremendous problem in the United States that affects over 15.5 million Americans annually and represents nearly $\$ 30$ billion in health-related expenses (Freeman et al. 1999). Whiplash is a frequent mechanism for producing neck pain, in which $19-60 \%$ of patients report persistent pain even two years after injury (Gargan \& Bannister 1994; Radanov et al. 1995). As such, whiplash associated disorders are responsible for nearly half of patient-care costs from motor vehicle accidents (Quinlan et al. 2004). In particular, the facet joint and its capsule have been demonstrated as the site of pain following whiplash in $25-62 \%$ of cases (Aprill \& Bogduk, 1992; Barnsley et al. 1994). In addition, comparative local anesthetic blocks identify the cervical facet joint as the source of pain

Address correspondence to Beth A. Winkelstein, $\mathrm{PhD}$, Department of Bioengineering, University of Pennsylvania, 240 Skirkanich Hall, 210 S. 33rd Street, Philadelphia, Pennsylvania, 19104-6321 Electronic mail: winkelst@seas.upenn.edu in as many as $60-72 \%$ of patients suffering from whiplash-associated neck pain (Barnsley et al. 1993; Lord et al. 1996). However, despite the high incidence of whiplash-associated facet-mediated pain, there still remains little known about the relationship between the structural response and the specific tissue sequelae which drive this persistent syndrome.

\section{Cervical Facet Joint Mechanics \& Context for Whiplash}

The facet joint kinematics during whiplash suggest capsule loading may play a role in the transduction of pain. Many volunteer and cadaveric studies have identified atypical motions of the cervical facet joint during simulations of the whiplash kinematic (Bogduk \& Yoganandan 2001; Cusick et al. 2001; Deng et al. 2000; Kaneoka et al., 1999; Ono et al. 1997; Panjabi et al. 1998; Sundararajan et al. 2004; Yoganandan and Pintar 1997). In the lower cervical spine, the facet capsular ligaments can, in some cases, exceed their physiologic range during 
whiplash-type loading (Grauer et al. 1997; Ito et al. 2004; Luan et al. 2000; Pearson et al. 2004; Stemper et al. 2005). During inertial loading of isolated cervical spines undergoing an $8 \mathrm{~g}$ acceleration, Pearson et al. (2004) estimated the C6/C7 facet capsular ligament peak strain to be $39.9 \pm 26.3 \%$. This significantly exceeded the strains $(10.7 \pm 9.3 \%)$ measured during normal spinal flexibility motions, leading those authors to postulate that excessive strain may cause capsular ligament injury during whiplash. While the cervical facet joint may undergo increased loading during whiplash, structural damage in the capsule during or following the whiplash kinematic has not been measured explicitly.

Many studies have investigated the mechanical properties of the isolated cervical facet joint to define the structural and material limits of the facet capsular ligament. Studies have defined the mechanical properties of the human cervical facet capsule at gross failure under tension and shear (Mykelbust et al. 1988; Siegmund et al. 2000, 2001; Winkelstein et al. 1999, 2000; Yoganandan et al. 2000). A number of these cadaveric studies also demonstrated mechanical injury of the facet capsule prior to gross ligament failure in both isolated and full cervical spine specimens (Panjabi et al. 1998; Siegmund et al. 2001; Winkelstein et al. 1999, 2000; Yoganandan et al. 2001). Partial failures, as defined by the authors of that work as a decrease in load with increasing displacement, were noted prior to gross failure of isolated cervical facet capsules (Siegmund et al. 2000, 2001; Winkelstein et al. 1999, 2000). The production of these partial ligament failures (previously termed "sub-catastrophic" failures) implies that the structure of the facet capsular ligament can be altered in the absence of gross ligament injury. While these studies collectively provide estimates of mechanical damage to the human facet joint and suggest thresholds for altered structural responses, the specific changes relevant to altered joint mechanics and tissue microstructure that may contribute to facet-mediated neck pain are undefined.

\section{Cervical Facet Joint Involvement in Pain}

Recent in vivo work has demonstrated facet joint distraction below tissue failure can initiate nociceptor activation and produce persistent pain. Electrophysiology studies in a caprine model have defined the responses of mechanoreceptive and nociceptive nerve fibers in the cervical facet capsule for applied tensile loading to the joint (Chen et al. 2005; Lu et al. 2005a, b). Specifically, Group III and IV afferent (pain) fibers have been identified throughout the $\mathrm{C} 5 / \mathrm{C} 6$ facet capsule and strain thresholds were defined for their excitation. Mechanoreceptor saturation and nociceptor activation was produced starting at strains of $44.2 \pm 16.7 \%$ and $47.2 \pm 9.6 \%$ respectively ( $\mathrm{Lu}$ et al. $2005 \mathrm{a}$ ). In a rat model of painful cervical facet joint distraction, persistent behavioral hypersensitivity directly related to the extent of tensile loading across the facet joint (Lee et al. 2004a, b). Rats undergoing sufficiently large subfailure distractions exhibited significantly elevated sensitivity (mechanical allodynia) over their naive counterparts up to 14 days after injury (Lee et al. 2004a). Additionally at this time point, spinal astrocytic activation was significantly elevated in the injured rats and dependent on distraction magnitude (Lee et al. 2004a). Together, this collection of studies has established subfailure tension of the cervical facet capsule to initiate nociceptive activation and produce persistent pain symptoms. However, an understanding of which specific tissue responses may transduce pain or drive the afferent sensitivity which is produced is still incomplete.

Mechanical studies of the isolated rat facet joint have further probed the relationship between persistent pain and mechanical injury. Yield $(570 \pm 80 \mu \mathrm{m})$, as defined by a significant decrease in stiffness with increasing distraction, was identified in the capsular ligament prior to its gross failure $(920 \pm 170 \mu \mathrm{m})$, partial failure $(690 \pm 130 \mu \mathrm{m})$, or any visible tearing (Quinn \& Winkelstein 2007). Recent efforts suggest that vertebral distractions of $700 \mu \mathrm{m}$ in vivo are sufficient to consistently induce elevated and persistent pain, while distractions at or below $300 \mu \mathrm{m}$ do not (Lee et al. 2007, 2004a). Given that ligament yield occurs between 460-700 $\mu \mathrm{m}$ of distraction (Quinn \& Winkelstein 2007), this suggests the capsule's collagen structure may be changing near the mechanical threshold for persistent pain. However, the specific functional, structural, and physiological consequences of ligament yielding or partial failure, if any, are also unknown.

\section{Soft Tissue Responses for Subfailure Loading or Injury}

Previously, it has been suggested that loading ligaments beyond their yield point results in permanent deformation (McMahon et al. 1999; Yoganandan et al. 1989). Many studies have shown that subfailure loading of ligaments produces laxity, decreases stiffness, and alters the viscoelastic response (Panjabi et al. 1996, 1999, 2001; Pollock et al. 2000; Provenzano et al. 2002). Pollock et al. (2000) reported $4.6 \pm 2.0 \%$ in residual laxity after distracting the human glenohumeral ligament to just below tissue failure. Using a similar study design, 
Iatridis et al. (2005) detected an increase in laxity following loading to $80 \%$ of the ultimate tensile strain in annulus fibrosus samples. Following application of a single subfailure distraction of variable magnitudes, Provenzano et al. (2002) determined the threshold for laxity to be $5.14 \%$ strain for rat medial collateral ligaments. Panjabi et al. (1996) also reported increased laxity and a decrease in stiffness in rabbit anterior cruciate ligaments, despite not detecting changes in the failure properties, after a stretch to $80 \%$ of the ultimate tensile strength. The structural response of the cervical facet capsule has not been defined after any subfailure distraction, and no study has placed these measures in the context of in vivo sequelae or microstructural responses.

To quantify the microstructural changes underlying an altered soft tissue response, the organization of collagen fibers has been measured during healing in rat and sheep tendons (Bruns et al. 2000; Gimbel et al. 2007, 2004; Thomopoulos et al. 2003). In separate studies, Gimbel et al. $(2007,2004)$ and Thompoulous et al. (2003) used a rat model of supraspinatus tendon detachment and repair, and demonstrated that the fiber alignment in the injured tissue was significantly less than control (uninjured) tissue initially following injury and repair, but progressively increased over time. Likewise, Bruns et al. (2000) showed that transection and partial resection of sheep Achilles tendon produced decreases in fiber alignment. Despite speculation that painful subfailure distraction of the facet capsule may induce microstructural damage of that ligament, the microstructural responses for that type of loading have not been quantified.

\section{Polarized Light Techniques to Quantify Soft Tissue Structure}

Polarized light techniques offer an effective method for determining fiber structure in soft tissue. Several studies have used these techniques to quantify the collagen fiber organization and crimp patterns in ligament and tendon (Boorman et al. 2006; Diamant et al. 1972; Dickey et al. 1998; Gathercole \& Keller 1991; Järvinen et al. 2004; Niven et al. 1982; Whittaker \& Canham 1991; Yeh et al. 2003). Because collagen fibers are naturally birefringent (i.e. light decomposes into two rays when passed through the tissue, owing to its structural anisotropy) (Vilarta \& Vidal Bde 1989), fiber orientation can be identified using polarizing filters. Birefringence can be further enhanced by staining sections with picrosirius red strain (Junqueira et al. 1979). Because the primary alignment of collagen fibers within tendons and ligaments is along the long axis of the ligament, it is most appropriate to determine the average variation of fiber alignment from the long axis of the ligament. This variation is often quantified by determining the angular deviation of fibers in a tissue section, and is averaged as a measure of the dispersion of fiber alignment within a given specimen or group (Gimbel et al. 2007, 2004; Thomopoulos et al. 2003).

While in vivo studies of the facet joint relate physiologic sequelae to pain symptoms and tissue mechanics, with a particular emphasis on measures of strain in the dorsal region of the capsule, that collective body of work has not investigated such relationships for all regions of the capsule. Because of this, it remains unclear whether the currently hypothesized mechanisms can be extended to have applicability to other anatomic regions of the capsule; further, it is also unknown whether such theories can be applied to the human joint. Both understanding the regional capsule biomechanics and tissue pathology in the context of subfailure loading and identifying potential indicators, mechanical or otherwise, to enable translation to the human condition will help integrate studies with animal and human cadaveric models. In this effort, the primary goal of this study was to investigate the cervical facet capsule's structure-function relationship in the context of a loading condition of the joint known to produce persistent pain (Lee et al. 2007, 2004a, b). This study characterizes aspects of damage to the rat facet capsule (previously inferred to occur by yield and partial tears during loading) for an acute time point following subfailure loading to define the joint response at low loads (laxity and stiffness) and identify the changes in fiber alignment. In order to focus on the mechano-nociceptive transduction relationship, measures were made acutely to minimize the potential confounding factors of collagen repair and inflammation. These complementary studies investigate several structural and mechanical measures within the context of a known painful condition to help understand the specific interplay between mechanics and pathophysiologic mechanisms which initiate persistent facet-mediated pain.

\section{METHODS}

Two separate studies were performed to explore the structure-function relationship of the rat cervical facet capsule during subfailure loading. The first study measured joint laxity, changes in stiffness, and regional strain variation for two subfailure loading distraction conditions in order to identify if, and to what extent, the structural responses of the facet capsule are altered during joint loading which produces pain. Based on findings from that joint 
mechanics study, a second in vivo study quantified collagen organization of the facet capsular ligament following matched painful tensile joint loading and compared those measurements to joints not exposed to loading. In both studies, the distraction magnitudes, loading direction, and rate, as well as spinal level, matched previous studies of the rat facet joint, to place data in context with previously established behavioral outcomes, physiologic responses, and tissue failure properties (Lee et al. 2004a, b; Quinn \& Winkelstein 2007). A vertebral distraction of $700 \mu \mathrm{m}$ (previously termed "subcatastrophic vertebral" or "SV") was applied across the $\mathrm{C} 6 / \mathrm{C} 7$ facet joint at $0.08 \mathrm{~mm} / \mathrm{s}$ in both studies. That subfailure distraction magnitude produces behavioral hypersensitivity (pain symptoms) that is sustained for at least two weeks and is considered a persistent syndrome (Lee et al. 2007, 2004a, b). In the structural mechanics study, an additional lower distraction magnitude $(300 \mu \mathrm{m}$, previously termed "physiologic vertebral" or "PV") was also investigated. PV distraction has been demonstrated not to produce behavioral hypersensitivity or sustained changes in the nociceptive responses of the central nervous system (Lee et al. 2004a, b), and in this study serves as a negative control for the application of greater joint distractions.

All experimental procedures were approved by the University of Pennsylvania Institutional Animal Care and Use Committee (IACUC) and carried out according to the guidelines of the Committee for Research and Ethical Issues of the International Association for the Study of Pain (Zimmerman 1983). Rats were housed under IACUC-approved conditions with free access to food and water.

\section{Facet Joint Structural Mechanics Study}

Specimen Preparation \& Experimental Setup. Male Holtzman rats $(\mathrm{n}=8)$ weighing $389 \pm 19 \mathrm{~g}$ were used for this study. The $\mathrm{C} 6 / \mathrm{C} 7$ spinal motion segment was harvested from isolated cervical spines, and all musculature was removed. The ligamentum flavum, interspinous ligament, supraspinous ligament, and dura matter were transected, and the carotid tubercles were removed from the motion segment. For this study, the left facet joint was removed en bloc at the pedicles and laminae (Figure 1).

In order to measure the mechanical response of isolated rat facet joints, a customized interface to an Instron 5865 (Instron Corporation, Norwood, MA) was utilized. The table-top Instron 5865, using a servo-motor and ballscrew drive, applied tension to the joint under displacement control $(0.02 \mathrm{~mm}$ accuracy) by gripping the laminae and transverse processes of the C6 and C7 vertebrae with microforceps (Figures $1 \& 2$ ). The superior grips, which held the C6 vertebra, attached to a $10 \mathrm{~N}$ load cell (Instron Corporation, Norwood, MA; accuracy of $0.25 \%$ measured value) and were displaced during loading, while the inferior grips (holding C7) remained stationary. To measure ligament deformation, fiduciary marks (26-38 per specimen) were made over the entire surface of the capsule for each specimen using a felt-tipped pen with a $200 \mu \mathrm{m}$ tip size (Figure 2).

Image \& Mechanical Data Acquisition. A photogrammetric imaging system was used to measure the ligament deformation in three dimensions (3-D) for the entire capsule surface during tensile loading. Ligament deformation was defined by motions of the fiduciary markers measured using stereophotogrammetry (Abdel-Aziz \& Karara 1971; Chen et al. 1994; Luo et al. 1993; Woltring 1980); two high-speed CCD cameras (Phantom v5.1 \& v4.3; Vision Research, Inc., Wayne, NJ) fitted with macro video zoom (6X) lenses (Edmund Optics, Inc., Barrington, NJ) were used. Both cameras in this study were set to a resolution of 28 pixels $/ \mathrm{mm}$ with an $800 \times 500$ pixel field of view. The rat cervical facet capsule consists of two, relatively flat dorsal and lateral surfaces oriented approximately $90^{\circ}$ relative to each other which meet to form a ridge (Lee et al. 2004a) (Figures 1a \& 1b). Because of this unique geometry, it is not possible to simultaneously image both the dorsal and lateral aspects of the capsule and reconstruct the capsule markers in 3-D using only two cameras. A camera positioning system was developed which enabled the pair of cameras to be locked into repeatable positions (Figures $2 \& 3$ ). The positioning system consists of two aluminum beams that are hinged about a central axis in the center of the specimen testing space (Figure 3). The camera mounting system is fixed to the base of the Instron, and the cameras can be fully adjusted in five degrees of freedom with respect to each positioning arm; the cameras can be rotated through a range of $110^{\circ}$ (Figure 3), and each beam can be repeatably positioned in $5^{\circ}$ increments about the testing space, enabling the cameras to be easily and consistently positioned $60^{\circ}$ apart from each other (Hatze 1988).

For this study, three repeatable positions were chosen to measure ligament deformation in the corresponding dorsal, dorsolateral ridge, and lateral regions of the ligament (Figure 1b). In one configuration for image acquisition, the two cameras were positioned to image the dorsal aspect of the 

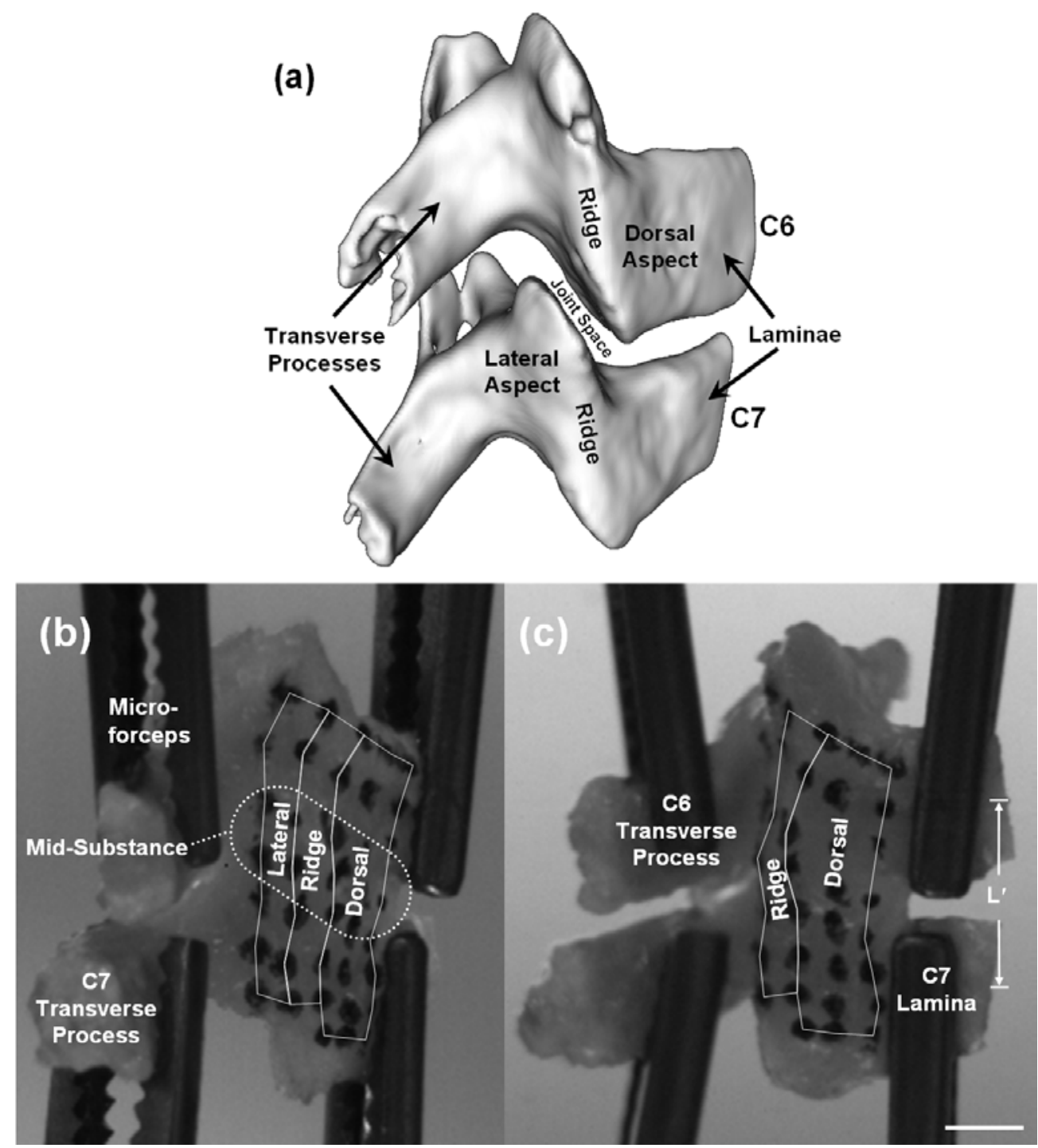

Figure 1. Rat facet joint bony structure and an image pair of the capsular ligament for a representative isolated cervical facet joint specimen $(\mathrm{AH})$. (a) A computed tomography isosurface of the bone of an isolated $\mathrm{C} 6 / \mathrm{C} 7$ joint showing the bony anatomy corresponding to the dorsal and lateral aspects of the capsule and the dorsolateral ridge along the articular column. Specimens were removed en bloc at the pedicles and laminae. (b) Camera 1 view of all three ligament regions: lateral, dorsolateral ridge, and dorsal. (c) Camera 2 showing both the C6 and C7 levels of the specimen gripped by the laminae and transverse processes. The reference position was set based on an intervertebral distance $\left(L^{\prime}\right)$ of $2.53 \mathrm{~mm}$. The calibration bar in (c) represents $1 \mathrm{~mm}$ and applies to (b) as well. Images were taken with the cameras in position $b$.

ligament (position $a$; Figure 3). The entire dorsolateral ridge (position $b$ ) was imaged by rotating the cameras clockwise $25^{\circ}$ about the specimen (Figure 1). The lateral aspect of the ligament was imaged by rotating the camera pair an additional $25^{\circ}$ (position $c$ ). Prior to specimen testing and image acquisition, a calibration frame with 56 known 3-D coordinates was imaged at each camera position ( $a$, $b, c)$ to establish transformation matrices for 3-D reconstruction. By combining these three camera positions at each distraction magnitude, the entire ligament surface was imaged and the 3-D positions fully defined for the analysis of capsule deformation.

To assess the effect of subfailure loading on the structural response of the facet joint, a tensile loading protocol was developed that distracted each ligament to the corresponding PV and SV magnitudes. The unloaded in vivo vertebral position of the $\mathrm{C} 6 / \mathrm{C} 7 \mathrm{rat}$ facet joint was used as the reference position prior to loading (Lee et al. 2007; Quinn \& Winkelstein 2007); the intervertebral distance $\left(L^{\prime}\right)$, defined as the spacing between the midpoints of the C6 and C7 laminae, 


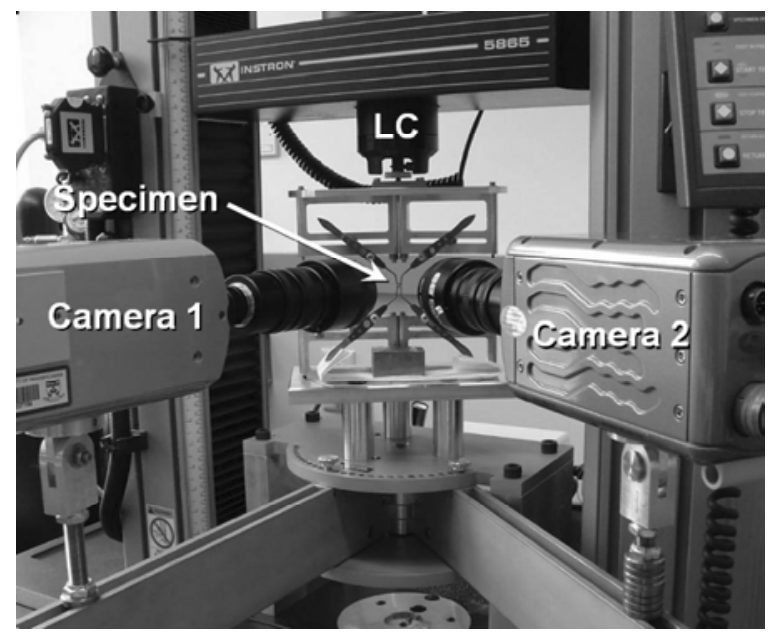

Figure 2. Specimen loaded in the Instron and imaged by cameras set in position $a$. The superior set of grips interface with the $\mathrm{C} 6$ end of the joint and were connected to a $10 \mathrm{~N}$ load cell (labeled $L C$ ). The inferior set of microforceps interface with the $\mathrm{C} 7$ portion of the joint.

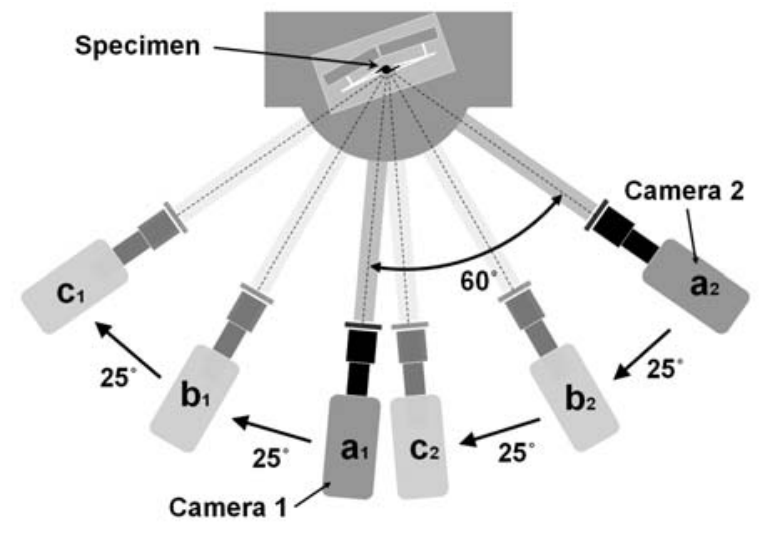

Figure 3. Schematic of the three sets of camera positions. At three distraction magnitudes (unloaded, PV, SV) stereoimages of the entire facet capsular ligament were acquired by acquisition in three different positions $(a, b, c)$. In position a, the cameras were positioned $60^{\circ}$ apart to images the dorsal aspect. To image the dorsolateral ridge of the capsule, both cameras were rotated $25^{\circ}$ clockwise. The cameras were rotated an additional $25^{\circ}$ to image the lateral aspect of the capsule.

was set to $2.53 \mathrm{~mm}$ (Figure 1c). The ligament was hydrated with saline and preconditioned with 30 cycles of distraction from 0 to $200 \mu \mathrm{m}$ (approximately $5 \%$ of the gross failure load) (Figure 4). After preconditioning, the specimen was allowed to rest for 8 minutes while images were taken of the ligament in each camera position to establish an unloaded reference position for each marker (Ref1; Figure 4). In the first test of the protocol (PV), a 300 $\mu \mathrm{m}$ distraction was applied at $0.08 \mathrm{~mm} / \mathrm{s}$. Stereoimages were acquired from each camera position $(a, b, c)$ while the specimen was held at the PV distraction for 4 minutes (Figure 4). The specimen was then returned to the unloaded configuration ( $0 \mu \mathrm{m}$ distraction), re-hydrated, and allowed to rest for 8 minutes. During that rest period, additional image pairs were acquired at all camera positions (Ref2; Figure 4). After the PV protocol, the specimen was distracted to $700 \mu \mathrm{m}$, held for 4 minutes while image pairs were again acquired, unloaded, and allowed to recover for 8 minutes (SV1; Figure 4). In the final portion of the loading protocol (SV2), the specimen was again distracted to $700 \mu \mathrm{m}$, held for 4 minutes, and returned to its reference position. No images were taken in SV2, as this protocol was designed to quantify any changes in the mechanical response following the SV1 distraction.

As each specimen was distracted during the loading portions of each protocol (PV, SV1, SV2), video and mechanical data were acquired. Force and displacement were recorded at $1 \mathrm{kHz}$ from the Instron using the Bluehill data acquisition software (Instron Corporation, Norwood, MA). Video data were also acquired during loading to detect any ligament tearing and evaluate if there was any slip of the specimen from the micro-forceps' grip during distraction. Acquisition of video data was triggered with the onset of Instron crosshead displacement, and data were collected at $100 \mathrm{~Hz}$ with the cameras in position $\mathrm{b}$ for this portion of the testing.

Analysis of Joint Structural Response. The mechanical response of the facet capsular ligament at low loads was assessed by determining joint laxity and changes in stiffness following each distraction magnitude (Figure 4). Joint laxity $\left(\delta L / L_{o}\right)$ was calculated based on a normalized change in ligament length at $0.05 \mathrm{~N}$ (Provenzano et al. 2002). The original ligament length $\left(L_{o}\right)$ was defined as the sum of the intervertebral length of $2.53 \mathrm{~mm}$ ( $L^{\prime}$; Figure 1c) and the displacement to $0.05 \mathrm{~N}$ of applied load during the PV distraction $\left(\delta_{P V}\right)$. Thus, joint laxity produced by a PV distraction $\left(\ell_{\mathrm{PV}}\right)$ was calculated as the difference between the displacements at $0.05 \mathrm{~N}$ for the PV distraction $\left(\delta_{P V}\right)$ and the subsequent SV1 distraction $\left(\delta_{S V I}\right)$, normalized by the original length of the ligament $\left(L_{o}\right)$ (Figure 4$)$ :

$\ell_{P V}=\frac{\partial L_{P V}}{L_{o}}=\frac{\delta_{S V 1}-\delta_{P V}}{\delta_{P V}+L^{\prime}}$ 


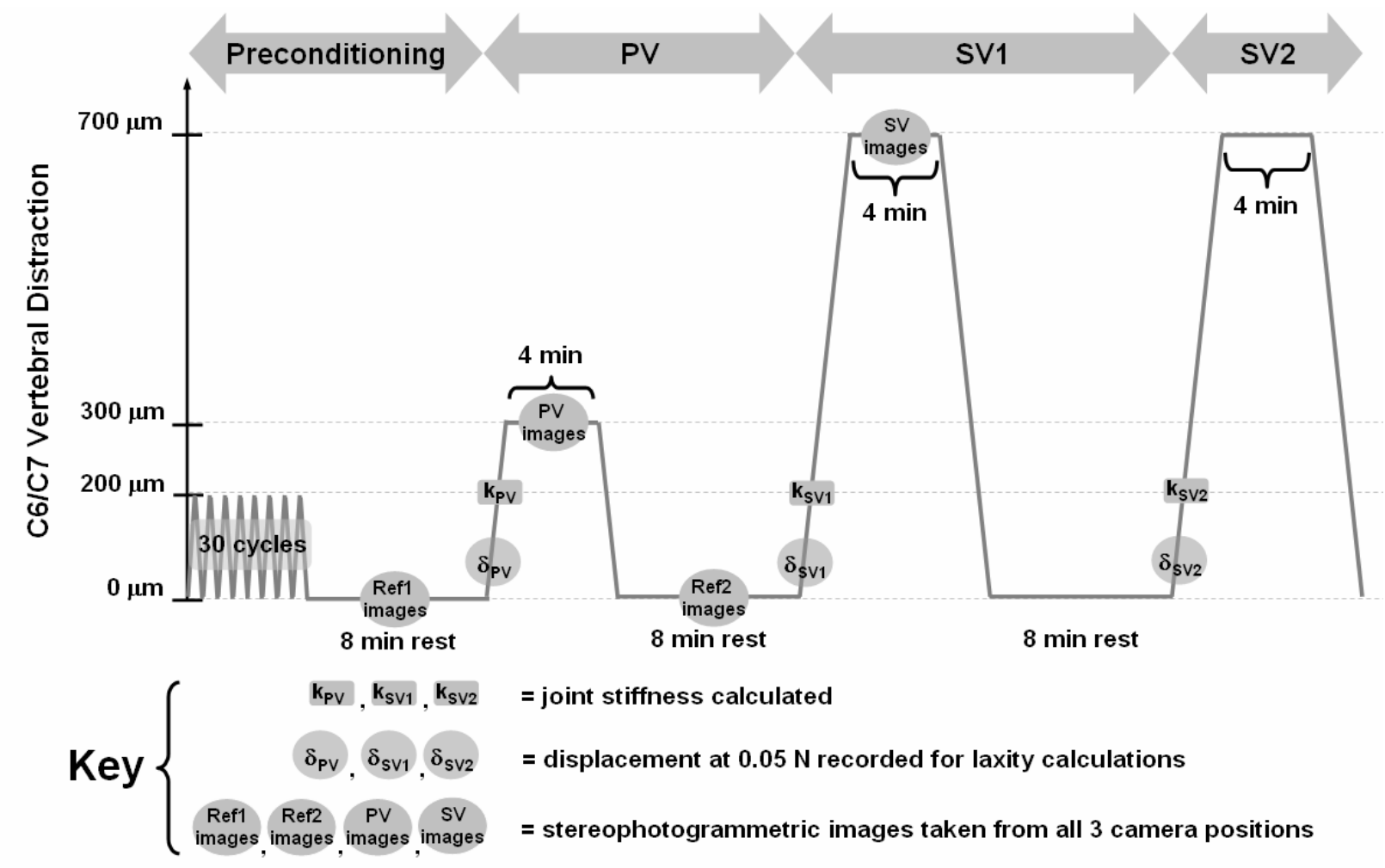

Figure 4. Specimen loading protocol. After 30 cycles of preconditioning and an 8 minute recovery, the joint was distracted to $300 \mu \mathrm{m}$ (PV) once and $700 \mu \mathrm{m}$ twice (SV1, SV2). Recovery periods of eight minutes separated the distractions. Stiffness at 200 $\mu \mathrm{m}(k)$ and displacement at $0.05 \mathrm{~N}(\delta)$ were both recorded for all three distractions, and these values were used to calculate laxity and the decrease in stiffness following the PV and SV1 distractions. Stereophotogrammetric images were taken at the reference positions, PV and SV1 distractions as indicated.

Similarly, the joint laxity after the first SV distraction $(\ell$ sv) was calculated based on the difference between the displacements at $0.05 \mathrm{~N}$ during the second $\mathrm{SV}$ distraction $\left(\delta_{\mathrm{SV} 2}\right)$ and the original displacement during the $\mathrm{PV}$ distraction $\left(\delta_{\mathrm{PV}}\right)$ :

$$
\ell_{S V}=\frac{\partial L_{S V}}{L_{o}}=\frac{\delta_{S V 2}-\delta_{P V}}{\delta_{P V}+L^{\prime}}
$$

The effect of subfailure distractions on ligament stiffness was investigated as an additional measure of structural change. Because the force-displacement curve is nonlinear at physiologic distractions $(0-300$ $\mu \mathrm{m})$, tangent stiffness was computed at each data point during distraction. Tangent stiffness was computed by differentiation of the forcedisplacement data through a centered finite difference approximation:

$k_{i}=\frac{F_{i+1}-F_{i-1}}{\delta_{i+1}-\delta_{i-1}}$ where the stiffness $\left(k_{i}\right)$ at a given time point, i, was calculated from the difference in force $(F)$ and displacement $(\delta)$ between the previous $(i-1)$ and subsequent $(i+1)$ time points. For the PV and two SV distractions (SV1, SV2), the tangent stiffness at $200 \mu \mathrm{m}$ was determined to assess how stiffness at low loads changes after distraction (Figure 4). The decrease in stiffness following PV distraction $\left(\Delta k_{P V}=\right.$ $\left.k_{S V I}-k_{P V}\right)$ and the corresponding decrease in stiffness following SV distraction $\left(\Delta k_{S V}=k_{S V 2}-k_{P V}\right)$ were computed to measure the extent of change in the lowload mechanical response. The maximum stiffness values computed during loading for each SV distraction were also compared to assess whether the decrease in stiffness following the first SV distraction $\left(\Delta k_{S V}\right)$ persisted beyond $200 \mu \mathrm{m}$.

Analysis of Capsule Strain. To identify the regions of the capsule that are most susceptible to any structural changes, as detected by laxity and decreases in stiffness, principal strain fields were calculated in the dorsal, dorsolateral ridge, and lateral aspects of the capsule. The stereoimages acquired at the reference $($ Refl $)$ and PV $(300 \mu \mathrm{m})$ and SV1 (700 $\mu \mathrm{m})$ distractions were used to define the 3-D capsule 
marker positions and calculate the corresponding principal strain fields in each region of the specimen. At each camera position, the centroid of every capsule marker visible by both cameras was digitized from the biplanar images taken at the two distractions (PV, SV1) and the reference position (Ref1) (Figure 4). Based on the calibration data for each camera position, these digitized marker positions were transformed into 3-D coordinates using ProAnalyst 1.0 software (Xcitex, Inc., Cambridge, MA); marker displacements were defined relative to the first reference position (Refl). A 4-node shell element mesh was created from the digitized nodes at each camera position; nodes were selected so that the three full-fields would include each of the dorsal aspect (position $a$ ), the dorsolateral ridge (position $b$ ), and the lateral aspect (position $c$ ), collectively spanning the ligament's entire surface. Using a customized isoparametric mapping program in Matlab (Matlab 7.2; Mathworks Inc., Natick, MA) and the 3-D nodal coordinates as inputs, the deformation gradients were calculated. From the deformations, the corresponding Lagrangian strain at each element was determined and principal strain fields were calculated. For each of the three regions of the capsule, the maximum principal strain was estimated at the PV and SV distractions, and the principal directions were assessed qualitatively.

Statistical Analyses. To determine whether the subfailure distractions (PV, SV) have different effects on the joint structural mechanical responses, the laxity, stiffness, and strain measurements were compared. Laxity $\left(\ell_{\mathrm{PV}}, \ell_{\mathrm{sv}}\right)$, and the force at 700 $\mu \mathrm{m}$ during the SV1 and SV2 distractions were compared using paired one-tailed t-tests. The force at $300 \mu \mathrm{m}$ during each distraction (PV, SV1, SV2) was compared using a repeated-measures ANOVA, with post-hoc Bonferroni-corrected paired two-tailed ttests. The decreases in stiffness following the PV and SV1 distractions ( $\Delta k_{P V} \& \Delta k_{S V}$, respectively) and the maximum stiffness during the SV1 and SV2 distractions were compared using paired t-tests. Maximum principal strains were compared using a two-factor ANOVA where capsule region (dorsal, dorsolateral ridge, lateral) and distraction magnitude (PV, SV) were the factors, followed by a post-hoc Bonferroni correction to compare differences among the three regions. All statistical tests were run using SYSTAT (SYSTAT Software Inc., Richmond, CA). Significance was defined as $\mathrm{p}<0.05$.

\section{Facet Capsule Fiber Organization Study}

Surgical Procedure \& Experimental Design. Male Holtzman rats $(\mathrm{n}=8 ; 416 \pm 28 \mathrm{~g})$ were used in the capsular ligament fiber organization study. To determine whether SV distraction is sufficient to produce changes in the capsular ligament structure, collagen fiber dispersion was quantified and compared for SV-distracted capsular ligaments and normal (uninjured) ligaments, as a measure of structural injury. Surgical methods to impose facet joint distraction in the rat have been previously detailed (Lee et al. 2004a, b). Briefly, under inhalation anesthesia (4\% halothane for induction, $2.5 \%$ halothane for maintenance), the $\mathrm{C} 6 / \mathrm{C} 7$ facet joints were exposed bilaterally. The $\mathrm{C} 6$ and $\mathrm{C} 7$ spinous processes were each rigidly attached to a customized loading device using micro-forceps (Figure 5). Tensile joint distraction was imposed at a rate of $0.08 \mathrm{~mm} / \mathrm{s}$ to match the loading rate used in the structural response study. The actual loading rate for this study was quantified using data from an LVDT (MicroStrain Inc., Burlington, VT; $0.16 \mu \mathrm{m}$

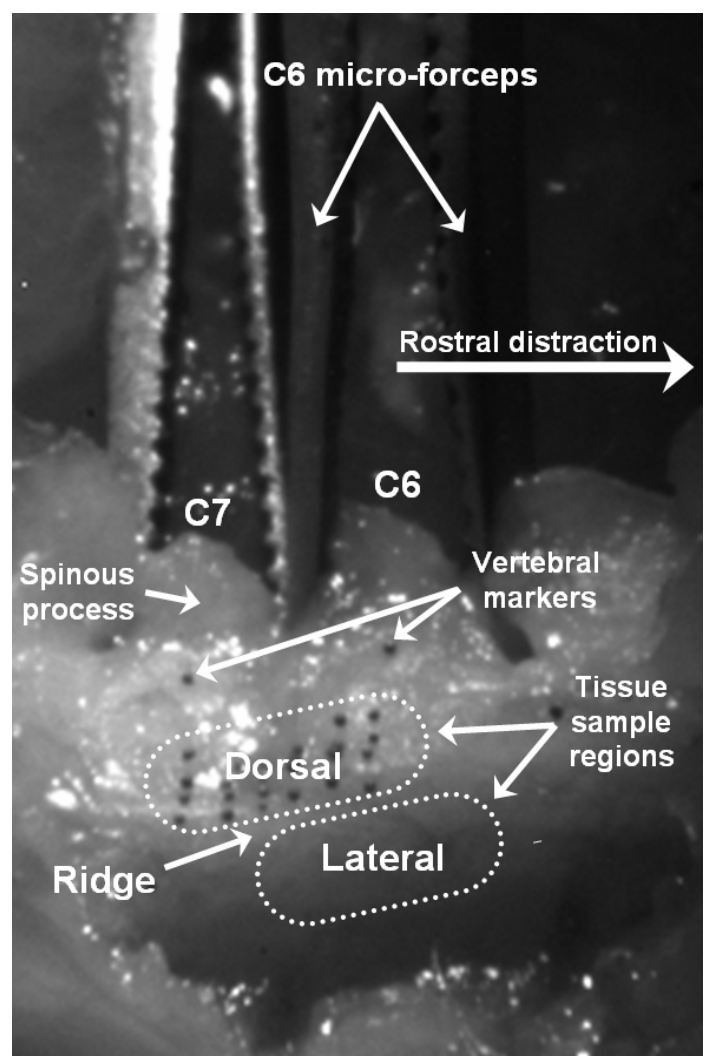

Figure 5. Lateral view of an in vivo facet joint exposure with device attachment. C7 micro-forceps were held fixed, while the $\mathrm{C} 6$ micro-forceps were translated rostrally, distracting the $\mathrm{C} 6 / \mathrm{C} 7$ facet joints. Vertebral markers were placed on the laminae to track bony motion. A grid of markers was also placed on the dorsal aspect of the capsule to measure deformation. Images for strain analysis in the fiber organization study were taken from the dorsal view only, and so, markers were not placed on the dorsolateral ridge or the lateral aspect of the joint. 
resolution) that was coupled to the C6 micro-forceps. Synchronized force data were measured using a load cell (Interface Inc., Scottsdale, AZ; $0.02 \mathrm{~N}$ resolution) that was coupled to the $\mathrm{C} 7$ micro-forceps. All mechanical data were acquired at $10 \mathrm{~Hz}$ using LabVIEW (National Instruments, Corp., Austin, TX).

To impose SV distraction across the joint, the C6 vertebra was translated by $700 \mu \mathrm{m}$ relative to the $\mathrm{C} 7$ vertebra, held for 30 seconds, and returned to its initial position. The resting initial position of the $\mathrm{C6} / \mathrm{C} 7$ intervertebral distance matched the ex vivo study and was set to $2.53 \mathrm{~mm}$. For each distraction study $(\mathrm{n}=4)$, polystyrene particles $(0.17 \pm 0.01 \mathrm{~mm}$ diameter; Spherotech, Inc., Libertyville, IL) were placed on the midline of each of the C6 and C7 vertebrae to track vertebral motions (Lee et al. 2004a, 2006) (Figure 5). Additional particles were affixed to the surface of the dorsal aspect of the capsule $(4 \times 6$ grid) (Figure 5), to measure capsule displacement fields. Vertebral and capsule markers were tracked during loading using Image Pro Plus software (Media Cybernetics, Inc., Silver Spring, MD). Maximum principal strain in the dorsal aspect of the capsule was calculated for each SV distraction using the positional coordinates of the capsule markers and LSDYNA software to calculate Lagrangian strains (LSTC; Livermore, CA) (Lee et al. 2004a, 2006; Winkelstein et al. 1999, 2000).

Tissue Preparation \& Data Acquisition. To quantify collagen fiber alignment, cervical spine segments (C4-T1) were removed en bloc one day after distraction and also from matched normal (unoperated) rats $(n=4)$. This time point for tissue harvest was selected to minimize the effects of scar tissue formation on measurements of collagen organization. Segments were fixed overnight in $4 \%$ paraformaldehyde, decalcified for seven days, and the $\mathrm{C} 6 / \mathrm{C} 7$ cervical spinal motion segment was isolated, dehydrated, and embedded in paraffin. Serial coronal sections $(8 \mu \mathrm{m})$ were taken of the right facet joint, spanning throughout both the dorsal and lateral aspects of the capsular ligament (Figures $1 \&$ 5), resulting in approximately 30 tissue sections for each specimen. Tissue was stained using $0.1 \%$ picrosirius red (Figure 6a), to enhance the collagen fiber birefringence for polarized light analysis (Thomopoulos et al. 2003). Microscopy and quantitative analysis methods were previously used to quantify the collagen orientation in the rat supraspinatus tendon (Gimbel et al. 2007, 2004; Thomopoulos et al. 2003). For each specimen, a tissue section from each of the dorsal and lateral aspects of the facet capsule was selected for analysis based on tissue integrity and quality of staining.

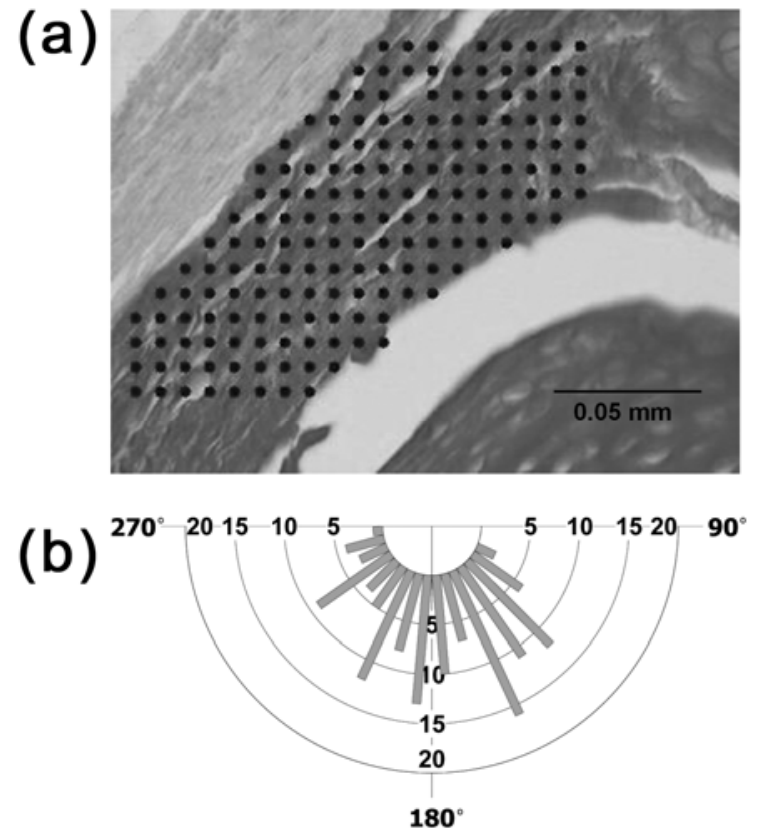

Figure 6. (a) Picrosirius red staining of the lateral aspect of a capsule specimen with the overlaid measurement grid. (b) Histogram showing the corresponding distribution of fiber alignment with a mean angular deviation of $18.7^{\circ}$.

Tissue sections were analyzed using a quantitative polarized light microscope (Model DM_LP, Leica Microsystems, Wetzlar, Germany) equipped with Pol objectives, a rotating analyzer and polarizer, and a digital microscope camera (MicroPublisher 5.0 MP, Qimaging, Burnaby, BC; $1280 \times 960$ pixels; 5.9 pixels $/ \mu \mathrm{m}$ resolution). Images were taken as the polarizer and analyzer were rotated through $90^{\circ}$, at $10^{\circ}$ increments, and subsequently repeated with a compensator.

Data \& Statistical Analysis. Customized Matlab code was used to quantify the angular orientation for a series of points within a grid (Thomopoulos et al. 2003 ); each grid contained an average of $109 \pm 53$ points, covering an average capsule area of $0.008 \pm 0.004 \mathrm{~mm}^{2}$ (Figure 6a). The angle at which the mean light intensity was a minimum served as a measure of the collagen orientation at that point (Gimbel et al. 2007, 2004; Thomopoulos et al. 2003). For each specimen, the angular deviation from the mean fiber direction was calculated separately for the dorsal and lateral regions using all grid points within each region, as a measure of the dispersion of fiber alignment (Oriana; Kovach Computing Services, Anglesey, Wales) (Figure 6). The mean angular deviation was compared across capsule region (dorsal, lateral) and group (SV, normal), using a twofactor ANOVA. Post-hoc t-tests with Bonferroni 
correction were used to compare differences within each group and region. All statistical calculations were performed using SYSTAT. Significance was defined as $\mathrm{p}<0.05$.

\section{RESULTS}

In both the joint structural mechanics study and the capsule fiber organization study, an SV distraction was imposed resulting in tensile loading of the $\mathrm{C} 6 / \mathrm{C} 7$ cervical facet joint. In the structural mechanics study, this distraction was defined as $700 \mu \mathrm{m}$ at 0.08 $\mathrm{mm} / \mathrm{s}$, while during the in vivo distraction in the fiber organization study the distraction was manually applied with a target rate of $0.08 \mathrm{~mm} / \mathrm{s}$ and magnitude of $700 \mu \mathrm{m}$. The resultant actual joint distraction applied in vivo was $740 \pm 22 \mu \mathrm{m}$ at a rate of $0.09 \pm 0.02 \mathrm{~mm} / \mathrm{s}$. The mean maximum principal strain in the dorsal aspect of the capsule at SV distraction was $50 \pm 13 \%$ for the structural mechanics study and $48 \pm 16 \%$ for the fiber organization study. In both studies, the location of maximum principal strain was in the mid-substance of the ligament. Given that the mean SV distractions differed by only $40 \mu \mathrm{m}$ and the resultant maximum principal strains were not significantly different, the loading of the joint in these two studies was considered equivalent.

\section{Facet Joint Structural Mechanics Study}

Force \& Failure. The joint forces for each specimen decreased after each distraction protocol (Table 1). In fact, the mean force at $300 \mu \mathrm{m}$ was significantly different for each protocol $(\mathrm{p}<0.002)$ : $0.35 \pm 0.16 \mathrm{~N}$ (PV), $0.30 \pm 0.15 \mathrm{~N}$ (SV1), and $0.04 \pm 0.02 \mathrm{~N}$ (SV2). In addition, the force at $700 \mu \mathrm{m}$ for the two SV distractions was also different; the force for SV1 distraction $(1.66 \pm 0.50 \mathrm{~N})$ was significantly higher $(\mathrm{p}<0.001)$ than that measured for SV2 $(1.17 \pm 0.41 \mathrm{~N})$ (Table 1). A decrease in force with increasing displacement was observed in half of the samples (AE, AI, AJ, AQ) during the SV1 distraction, at a mean load of $1.68 \pm 0.46 \mathrm{~N}$ and joint distraction of $562 \pm 91 \mu \mathrm{m}$. During distraction, tearing was visible on video only in those four specimens with partial failure noted in the force-displacement trace. All tears occurred at the mid-substance of the ligament and were located in the lateral aspect or the dorsolateral ridge for all four specimens (Figure 1b).

Laxity \& Stiffness. Changes in the structural response were greatest following SV distraction with laxity increasing and stiffness decreasing more than following PV distraction (Figure 7). After PV distraction, mean laxity $\left(\ell_{P V}\right)$ was $0.99 \pm 0.45 \%$, and stiffness decreased $\left(\Delta k_{P V}\right)$ by $0.36 \pm 0.22 \mathrm{~N} / \mathrm{mm}$ (Tables $2 \& 3$ ). Following the SV1 distraction, mean laxity $\left(\ell_{S V}\right)$ was greater $(7.30 \pm 3.01 \%)$, and the decrease in stiffness $\left(\Delta k_{S V}\right)$ was also greater $(1.47 \pm 0.86 \mathrm{~N} / \mathrm{mm})$ (Tables $2 \& 3)$. Both of these changes were significant, with laxity from SV distraction being greater $(p<0.001)$ than that produced by PV distraction, and the corresponding decrease in stiffness also significant $(p=0.002)$ compared to PV. While the stiffness at $200 \mu \mathrm{m}$ decreased significantly more following SV distraction, the maximum tangent stiffness calculated during the first and second SV distractions (5.39 \pm 1.87 for SV1, $6.18 \pm 2.28$ for SV2) was not significantly different (Table 4, Figure 7). In fact, in six of the eight specimens the maximum tangent stiffness was actually higher during the second SV distraction (Table 4).

Facet Capsule Strain. Maximum principal strain was greatest in the dorsal aspect of the capsule for both PV and SV distraction (Table 5). Mean error in strain measurements was defined by calculating principal strain at the unloaded reference position

Table 1. Force $(\mathrm{N})$ during PV, SV1 and SV2 distractions.

\begin{tabular}{|c|c|c|c|c|c|}
\hline \multirow[t]{2}{*}{ Specimen } & \multicolumn{3}{|c|}{$300 \mu \mathrm{m}$} & \multicolumn{2}{|c|}{$700 \mu \mathrm{m}$} \\
\hline & PV & SV1 & SV2 & SV1 & SV2 \\
\hline $\mathrm{AB}$ & 0.15 & 0.12 & 0.03 & 0.83 & 0.60 \\
\hline$A D$ & 0.34 & 0.23 & 0.05 & 1.86 & 1.45 \\
\hline $\mathrm{AE}$ & 0.62 & 0.53 & 0.01 & 1.23 & 0.79 \\
\hline $\mathrm{AH}$ & 0.29 & 0.25 & 0.05 & 1.78 & 1.08 \\
\hline $\mathrm{Al}$ & 0.22 & 0.18 & 0.04 & 1.73 & 1.08 \\
\hline AJ & 0.49 & 0.46 & 0.02 & 2.27 & 1.74 \\
\hline AP & 0.22 & 0.19 & 0.07 & 1.34 & 0.95 \\
\hline$A Q$ & 0.46 & 0.41 & 0.05 & 2.22 & 1.65 \\
\hline Mean $\pm S D$ & $0.35 \pm 0.16$ & $0.30 \pm 0.15$ & $0.04 \pm 0.02$ & $1.66 \pm 0.50$ & $1.17 \pm 0.41$ \\
\hline
\end{tabular}



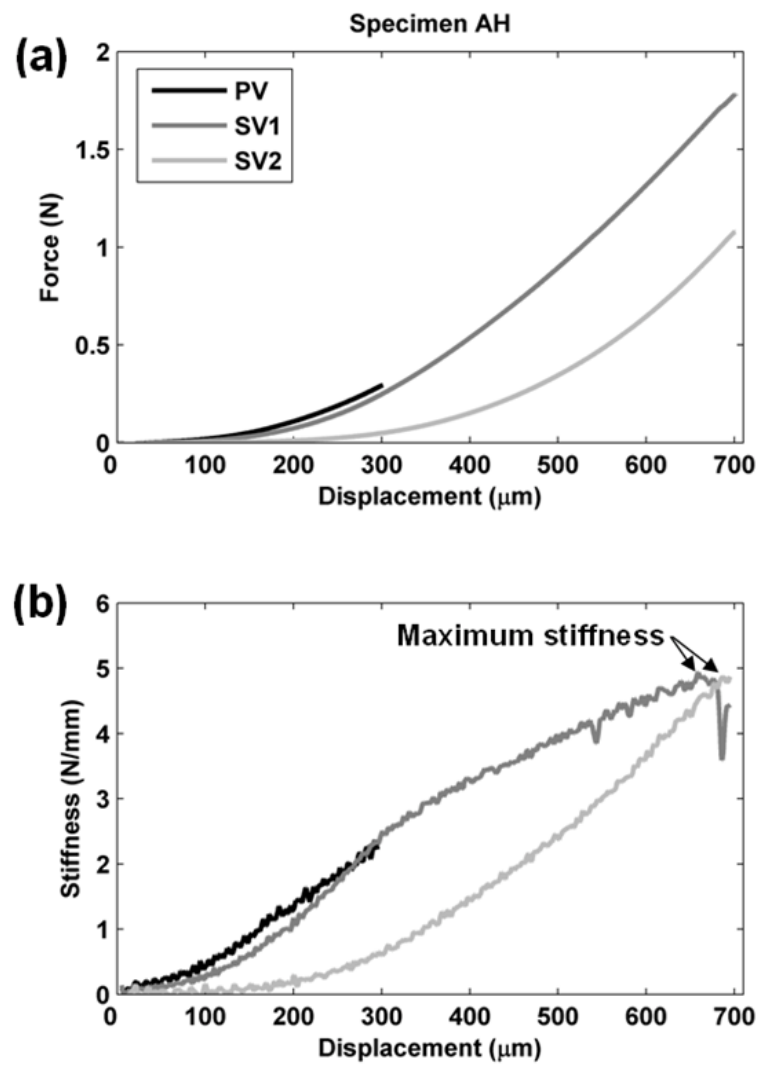

Figure 7. Structural response of Specimen AH during tensile distraction, for a PV distraction (black), and the two subsequent SV distractions (dark \& light gray). (a) During the SV2 distraction (light gray), the increased laxity is apparent by the low loads $(<400 \mu \mathrm{m})$ of displacement. (b) Stiffness is also lower at displacements below $500 \mu \mathrm{m}$ during the SV2 distraction; however, the difference between the maximum stiffness of the two SV distractions is not significant.

after the PV distraction (Ref2, Figure 4). This mean error in the principal strain measurements was estimated as $2.2 \pm 1.6 \%$ strain and could be attributed to digitization and 3-D reconstruction of the fiduciary markers. At the PV distraction, maximum principal strain was $21 \pm 4 \%$ in the dorsal aspect, $17 \pm 4 \%$ in the dorsolateral ridge, and $18 \pm 4 \%$ in the lateral aspect of the ligament (Table 5). The corresponding mean maximum principal strain at SV was $50 \pm 13 \%$ in the dorsal aspect, $35 \pm 6 \%$ in the dorsolateral ridge, and $43 \pm 11 \%$ in the lateral aspect of the ligament. Based on all regions of the capsule, maximum principal strain was significantly higher at SV compared to PV $(p<0.001)$. Regional differences in maximum principal strain were only significant $(\mathrm{p}=0.012)$ between the dorsal aspect $(50 \pm 13 \%)$ and the dorsolateral ridge $(35 \pm 6 \%)$ for SV distraction.
Table 2. Laxity (\%) after PV and SV distractions.

\begin{tabular}{ccc}
\hline Specimen & After PV & After SV1 \\
\hline AB & 1.79 & 7.14 \\
$A D$ & 1.55 & 5.77 \\
AE & 0.77 & 14.4 \\
AH & 1.02 & 5.73 \\
Al & 0.81 & 5.65 \\
AJ & 0.51 & 6.83 \\
AP & 0.84 & 5.05 \\
AQ & 0.66 & 7.81 \\
\hline Mean \pm SD & $\mathbf{0 . 9 9 \pm 0 . 4}$ & $\mathbf{7 . 3 0} \pm \mathbf{3 . 0 1}$
\end{tabular}

The location of maximum principal strain was consistently on the mid-substance of the dorsal aspect of the ligament in six of the eight specimens for both the PV and SV distractions (Figure 8). In one specimen $(A B)$, the maximum principal strain was located in the mid-substance of the lateral aspect for the PV distraction, but the location of maximum principal strain changed to the mid-substance of the dorsolateral ridge for SV. In Specimen AJ, the maximum principal strain at PV was located in the mid-substance of the dorsal aspect, but changed to the mid-substance of the lateral aspect at SV. While the magnitudes of principal strain differed between the PV and SV distractions, there was little variation in the principal directions between the two distraction magnitudes in the majority of elements of the grid. However, for both PV and SV distractions, principal strain direction was more aligned with the direction of loading in the dorsal aspect than in the lateral aspect of the joint (Figure 8).

\section{Facet Capsule Fiber Organization Study}

Mean distraction of the $\mathrm{C} 6 / \mathrm{C} 7$ facet joint was $740 \pm 22$ $\mu \mathrm{m}$, and resulted in $48 \pm 16 \%$ maximum principal strain in the dorsal aspect of the capsule. In normal (uninjured) samples, mean angular deviation of the collagen fibers in the dorsal region of the capsule $\left(16.7 \pm 5.6^{\circ}\right)$ was greater than that in the lateral region $\left(12.8 \pm 3.3^{\circ}\right)$, but this difference was not significant (Figure 9). Fiber dispersion increased in both the dorsal and lateral regions of the capsule after SV distraction (Figure 9). However, this increase was only significant relative to normal $(\mathrm{p}=0.004)$ in the lateral region of the facet capsule (Figure 9). SV joint distraction produced the greatest fiber dispersion in the dorsal region of the capsule $\left(23.0 \pm 4.9^{\circ}\right)$, which was significantly $(\mathrm{p}=0.008)$ greater than the corresponding dispersion in the lateral region $\left(16.8 \pm 2.6^{\circ}\right)$ (Figure 9). 
Table 3. Ligament stiffness $(\mathrm{N} / \mathrm{mm})$ at $200 \mu \mathrm{m}$ of distraction.

\begin{tabular}{cccccc}
\hline Specimen & Original & After PV & After SV1 & $\begin{array}{c}\text { Decrease } \\
\text { after PV }\end{array}$ & $\begin{array}{c}\text { Decrease } \\
\text { after SV1 }\end{array}$ \\
\hline $\mathrm{AB}$ & 0.70 & 0.48 & 0.10 & 0.22 & 0.60 \\
$\mathrm{AD}$ & 1.65 & 0.99 & 0.16 & 0.66 & 1.49 \\
$\mathrm{AE}$ & 3.00 & 2.25 & 0.02 & 0.75 & 2.98 \\
$\mathrm{AH}$ & 1.35 & 1.08 & 0.21 & 0.27 & 1.14 \\
$\mathrm{Al}$ & 0.97 & 0.75 & 0.16 & 0.22 & 0.81 \\
$\mathrm{AJ}$ & 2.39 & 2.07 & 0.06 & 0.32 & 2.33 \\
$\mathrm{AP}$ & 0.91 & 0.77 & 0.30 & 0.14 & 0.61 \\
$\mathrm{AQ}$ & 1.99 & 1.67 & 0.17 & 0.32 & 1.82 \\
\hline Mean士SD & $\mathbf{1 . 6 2 \pm 0 . 8 0}$ & $\mathbf{1 . 2 6 \pm 0 . 6 6}$ & $\mathbf{0 . 1 5 \pm 0 . 0 9}$ & $\mathbf{0 . 3 6 \pm 0 . 2 2}$ & $\mathbf{1 . 4 7 \pm 0 . 8 6}$ \\
\hline
\end{tabular}

\section{DISCUSSION}

In these mechanical and histologic studies, the structural response at low loads and the collagen fiber organization of the cervical facet capsular ligament are altered for subfailure loading conditions which have been previously shown to produce pain (Lee et al., 2007, 2004a, b). Specifically, the laxity and decrease in stiffness following SV distraction were significantly greater than following PV distraction (Tables $2 \& 3$, Figure 7). These mechanical changes are also coupled with a significant increase in the dispersion of collagen fibers produced in the lateral aspect of the ligament following a matched in vivo SV distraction (Figure 9). Interestingly, in addition to these structural and microstructural findings for $\mathrm{SV}$ distraction, the maximum principal strain in the capsule at SV $(50 \pm 12 \%)$ was predominantly located in the dorsal aspect of the ligament, rather than in the lateral aspect where the most significant changes in fiber organization were detected. Maximum principal strain $(48 \pm 16 \%)$ in the fiber orientation study was not significantly different from that in the structural mechanics study at SV distraction and provides evidence of equivalent loading in these two studies.

Mechanical differences measured between PV and SV distractions suggest that loading which produces a painful injury also produces a change in the ligament structure. The average decrease in stiffness following SV distraction was four times greater than that after PV distraction, and mean laxity increased seven-fold between SV and PV distractions (Tables 2 \& 3). These significant changes between the two subfailure distractions suggest that displacements between $300-700 \mu \mathrm{m}$ produce damage in the capsule tissue. During tensile failure of the rat facet capsule, ligament yield has been identified for joint distractions ranging from 460 to $700 \mu \mathrm{m}$ (Quinn \& Winkelstein 2007). Given that the range of distraction magnitudes for yield of this facet capsule falls between SV and PV magnitudes, it is possible that ligament yield may correspond to, and represent, the onset for changes in laxity and stiffness. Provenzano et al. (2002) defined a strain threshold for laxity in the rat medial collateral ligament by imposing variable strain magnitudes. Due to differences in ligament structure, failure properties, and strain measurement techniques, it is not meaningful to directly compare the strain threshold for that work with the strain data of the present study. However, it should be noted that laxity in that tissue did not exceed $2 \%$ for any distractions below the threshold (Provenzano et al. 2002); similarly in our study, laxity following the PV distraction remained below $1.79 \%$ for all specimens (Table 2). Together, these data lend further support to a hypothesis that a threshold for these structural changes exists between PV and SV distractions, and may relate to the initiation of pain.

Table 4. Maximum ligament stiffness (N/mm) during SV distractions.

\begin{tabular}{ccc}
\hline Specimen & SV1 & SV2 \\
\hline AB & 2.09 & 3.55 \\
AD & 5.32 & 5.99 \\
AE & 5.12 & 5.32 \\
AH & 4.93 & 4.87 \\
Al & 6.03 & 5.44 \\
AJ & 8.57 & 10.23 \\
AP & 4.37 & 4.95 \\
AQ & 6.69 & 9.08 \\
\hline Mean \pm SD & $\mathbf{5 . 3 9 \pm 1 . 8 7}$ & $\mathbf{6 . 1 8 \pm 2 . 2 8}$ \\
\hline
\end{tabular}


Table 5. Maximum principal strain (\%) during PV and SV distractions.

\begin{tabular}{ccccc}
\hline Specimen & $\begin{array}{c}\text { Lateral } \\
\text { Aspect }\end{array}$ & $\begin{array}{c}\text { Dorsolateral } \\
\text { Ridge }\end{array}$ & $\begin{array}{c}\text { Dorsal } \\
\text { Aspect }\end{array}$ & $\begin{array}{c}\text { Entire } \\
\text { Ligament }\end{array}$ \\
\hline AB & 19 & 19 & 13 & 19 \\
AD & 17 & 11 & 21 & 21 \\
AE & 14 & 18 & 24 & 24 \\
AH & 21 & 14 & 22 & 22 \\
Al & 13 & 16 & 22 & 22 \\
AJ & 14 & 16 & 18 & 18 \\
AP & 17 & 16 & 19 & 19 \\
AQ & 26 & 24 & 28 & 28 \\
\hline PV Mean \pm SD & $\mathbf{1 8 \pm 4}$ & $\mathbf{1 7 \pm 4}$ & $\mathbf{2 1 \pm 4}$ & $\mathbf{2 2 \pm 3}$ \\
\hline \hline AB & 27 & 35 & 34 & 35 \\
AD & 38 & 23 & 46 & 46 \\
AE & 49 & 35 & 51 & 51 \\
AH & 53 & 32 & 58 & 58 \\
Al & 33 & 40 & 57 & 57 \\
AJ & 42 & 39 & 37 & 42 \\
AP & 42 & 35 & 42 & 42 \\
AQ & 63 & 40 & 72 & 72 \\
\hline SV Mean \pm SD & $\mathbf{4 5 \pm 1 1}$ & $\mathbf{3 5 \pm 6}$ & $\mathbf{5 0 \pm 1 3}$ & $\mathbf{5 0 \pm 1 2}$ \\
\hline
\end{tabular}

The differences in stiffness between the first and second SV distractions provide evidence of the microstructural changes to the ligament's collagen matrix. While there is a significant decrease in stiffness after subfailure (SV1) distraction $(1.47 \pm 0.86$ $\mathrm{N} / \mathrm{mm}$ ) at $200 \mu \mathrm{m}$ (Table 3), the difference in stiffness between the SV1 and SV2 distractions is less pronounced as displacement approaches $700 \mu \mathrm{m}$ (Figure 7). In fact, near $700 \mu \mathrm{m}$ maximum tangent stiffness actually increased in the SV2 distraction relative to SV1 for six specimens (Table 4), despite lower stiffness at $200 \mu \mathrm{m}$ (Table 3). This surprising finding suggests that collagen fiber integrity in the direction of loading may not be compromised during these distractions but rather, that secondary microstructures such as collagen crosslinks, elastin, minor collagens, or circumferentially-oriented collagens may in fact be damaged during SV loading. These modifications may result in changes in the recruitment of collagen fibers during loading and the altered collagen alignment measured in this study for in vivo SV joint distraction (Figure 9). Uchiyama et al. (2005) noted a similar trend in the medial collateral ligament of the first metatarsophalangeal joint in human cadavers, with collagen structure abnormalities due to hallux valgus of the foot. These pathological ligaments exhibited lower stiffness in the toe region relative to normal samples and increased fiber dispersion.
While the rate, magnitude, and direction of loading in these studies matched previous work (Lee et al. 2007, 2004a, b; Quinn \& Winkelstein 2007), the distraction hold time for the ex vivo study differed due to experimental issues. During isolated specimen testing, image acquisition and camera positioning at $\mathrm{PV}$ and SV distractions required a hold time of four minutes; however, during the in vivo studies this hold time was only 30 seconds. The effect of the additional relaxation time on the structural changes in vivo is unknown. However, given no ligament failures were observed during this extended hold time in the isolated studies, and because the majority of relaxation occurred prior to 30 seconds, it is unlikely that further damage to the collagen matrix occurred between 30 seconds and 4 minutes in those tests. While the ligaments were allowed to recover at $0 \mu \mathrm{m}$ of distraction for 8 minutes between protocols, the effect of a greater recovery time was not investigated here. However, in previous studies of laxity following subfailure injury, no significant recovery of injury-induced laxity was found for up to 60 minutes after the subfailure loading (Iatridis et al. 2005; Pollock et al. 2000). The evidence of partial tears and yielding during distraction (Quinn \& Winkelstein, 2007) and the resultant fiber disorganization measured 24 hours after injury in the current in vivo study suggest the mechanical changes between SV and PV distraction magnitudes are a result of injury rather than a lack of recovery. While 

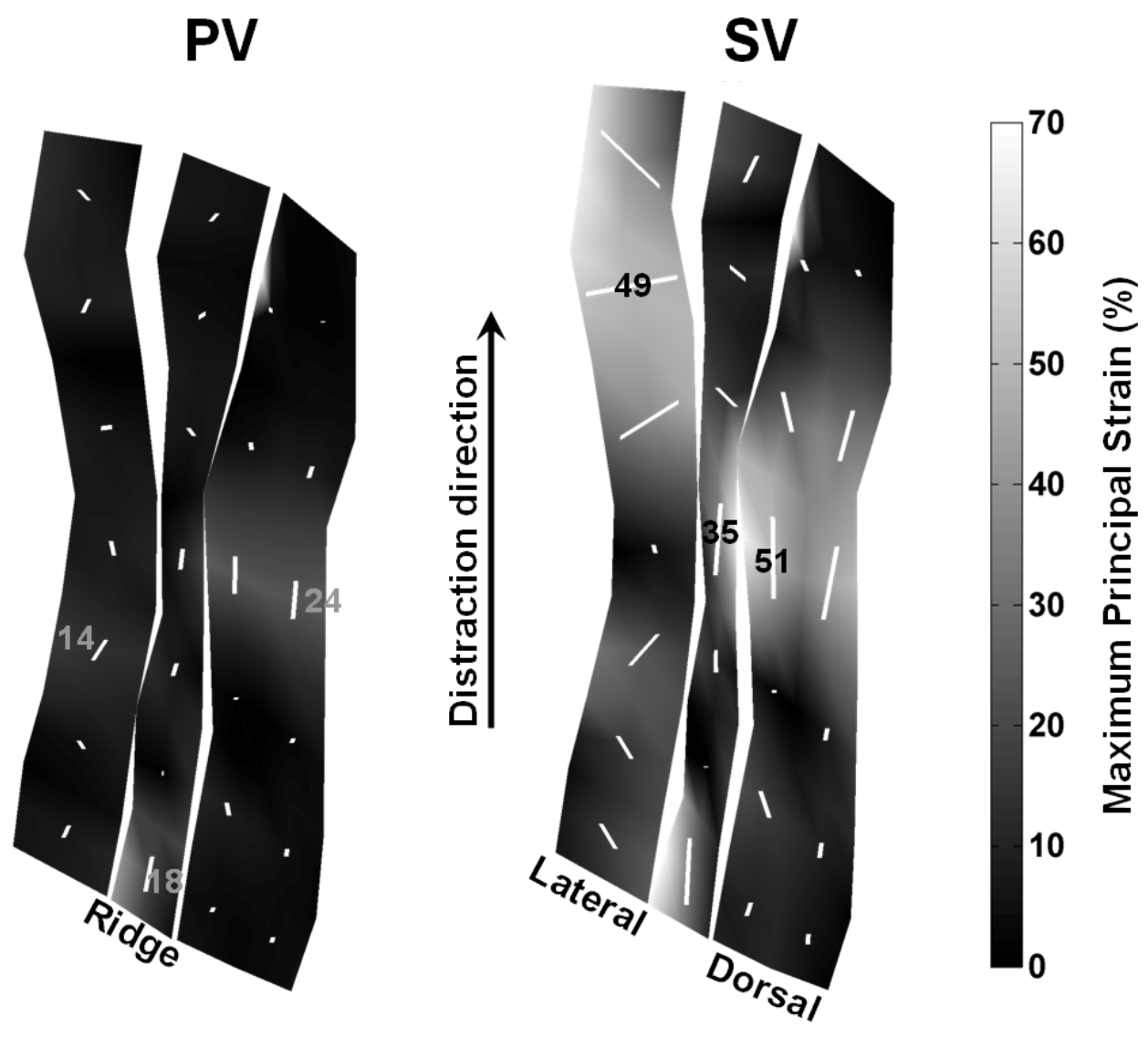

Figure 8. First principal strain field with principal strain directions at PV and SV distractions for a representative specimen (AE). Each region (lateral, dorsolateral ridge, dorsal) has been rotated to enable a full view of the strain field, and the location of maximum principal strain (\%) in each region is labeled with its value. The maximum principal strain for the entire ligament was in the dorsal aspect of most joints $(51 \%$, here). Principal strain in the dorsal aspect was generally oriented in the direction of distraction; however, in the lateral aspect, principal strains were often not aligned with that direction.

both structural and ligament fiber changes were detected in our studies, chronic studies investigating the effects of both the persistent putative cascades and beneficial responses of ligament healing, as well as tissue scarring, afferent plasticity, joint laxity, and fiber disorganization are needed to provide additional insight into the mechanisms of facet-mediated persistent pain.

Partial ligament failure occurred during some tests and was expected based on previous findings with isolated failure studies of facet capsular ligaments (Quinn \& Winkelstein 2007). During tensile failure of the isolated rat cervical facet joint, the first instance of failure occurred at $690 \pm 130 \mu \mathrm{m}$ and $2.20 \pm 0.78$ N (Quinn \& Winkelstein 2007). Given this mean distraction magnitude, and assuming a normal distribution, approximately half of all specimens would be expected to exhibit partial failure below $700 \mu \mathrm{m}$ of distraction. Accordingly, partial failure did occur in four of eight samples in this ex vivo study during the SV1 distraction, at $562 \pm 91 \mu \mathrm{m}$ and $1.68 \pm 0.46 \mathrm{~N}$. This study also supports the hypothesis that ligament failure is not a requirement for facet-mediated persistent pain. In the isolated specimens with partial failure, tearing was seen in the lateral region and the dorsolateral ridge. The location of these tears suggests the lateral and dorsolateral ridge regions of the rat facet joint are more susceptible to structural damage and injury. While detecting these partial tears during in vivo distractions is not possible due to load sharing with other spinal structures and limited capsule visualization, the in vivo data demonstrate similar regional patterns of damage with significant increases in the disorganization of collagen fibers in the lateral aspect of the facet capsule, but not the dorsal aspect (Figure 9).

To our knowledge, this is the first study to investigate strain in all regions of the entire facet capsule. Historically, strain measurements of the cervical facet 
capsule in the human have focused on the lateral aspect of the joint (Pearson et al. 2004; Siegmund et al. 2000; Winkelstein et al. 1999), while animal models have focused mainly on the dorsal aspect (Lee et al. 2004a, b; Lu et al. 2005a, b). These approaches have been largely constrained by experimental challenges in maintaining relevant physiological structures in cadavers during whiplash simulations, and minimizing the invasiveness of animal surgeries. Here, the structural mechanics study measured strain in both aspects of the joint, in addition to the transitional ridge where the two regions meet. In studies of the lateral aspect of the human facet capsule, there were no detectable trends in the location of maximum principal strain during failure in shear or tension (Winkelstein et al., 1999; Siegmund et al., 2000). In addition, no significant trend in the location of maximum principal strain in the dorsal aspect of the joint has been detected in either rat or caprine models of this joint (Lee et al. 2006; Lu et al. 2005a). When considering the entire ligament, however, regional differences are apparent. In this study, maximum principal strain at SV was significantly higher in the dorsal aspect of the capsule compared to the dorsolateral ridge $(\mathrm{p}=0.012)$, and the maximum principal strain of the entire ligament was located in the mid-substance of the dorsal aspect for six of the eight specimens. Given regional variability in the location of partial failures, collagen disorganization, and maximum principal strain, thresholds for pain in animal models will require investigation of the entire capsule. While histological and mechanical data come from all regions of the capsule in a variety of species, detailed quantitative scaling relationships (geometric and otherwise) are needed to extrapolate the understanding of the physiologic mechanisms defined in animal models for meaningful interpretation with regard to the human facet joint.

The maximum principal strains in the dorsal aspect of the capsule at SV distraction in these studies ( $48 \pm 16 \%$ in vivo; $50 \pm 13 \%$ ex vivo) suggest this distraction magnitude is capable of nociceptive activation in addition to producing persistent pain. Electrophysiological studies of the joint document mechanoreceptor discharge saturation and nociceptor activation thresholds at maximum principal strains of $44.2 \pm 16.7 \%$ and $47.2 \pm 9.6 \%$, respectively in the goat (Lu et al. 2005a). These strains are exceeded at SV distractions as measured in this study. Furthermore, histological work has identified both mechanoreceptors and nociceptors throughout the capsule in human, goat, rabbit, and rat facet joints (Cavanaugh et al. 1996, 1989; Chen et al. 2006; McLain 1994; Inami et al. 2001). Accordingly, this

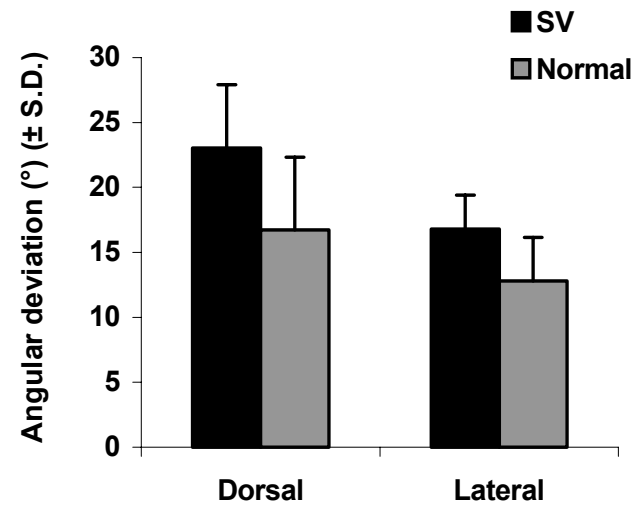

Figure 9. Mean angular deviation in the $\mathrm{C} 6 / \mathrm{C} 7$ facet capsule dorsal and lateral regions for normal and after SV distraction. Significant differences $\left({ }^{*} \mathrm{p}<0.008\right)$ are indicated.

collection of studies indicates capsule strain for SV distraction may be capable of saturating mechanoreceptors and likely initiating nociceptive firing, and suggests nociceptive activation may lead to persistent pain symptoms. While SV distractions in the rat also produce persistent behavioral hypersensitivity, the mean maximum principal strain at SV ranged between 23-28\% (Lee et al. 2004a, 2006). In those previous studies, the dorsal aspect of the capsule was covered by as few as one to four elements. Given the variation in the strain field (Figure 8) using a finer mesh (8-14 elements), it is not surprising that maximum principal strain values here are higher using an improved nodal resolution. Nonetheless, significantly increased laxity, decreased stiffness, and increased fiber dispersion are found at magnitudes of loading which have been shown to excite nociceptive fibers and create persistent pain.

This study detected significantly increased collagen disorganization in the rat cervical facet capsular ligament following subfailure distraction (Figure 9). Increased collagen fiber dispersion could arise from microstructural failure or increased undulation, and would suggest additional distraction is required for those fibers to bear load. This change in fiber response may manifest as the increase in laxity detected during the ex vivo testing of isolated joints in this study (Table 2). While these findings define fiber dispersion in the facet joint capsule, additional studies are needed to assess which aspects of the ligament's microstructural integrity may be damaged during these loading scenarios, to define the fiber kinematics during loading and the mechanisms of injury, and to establish an explicit relationship between microstructure and joint function. 
Additionally, while this study quantifies changes in the load-bearing collagen matrix, it is unclear how these changes directly affect nerve fibers and their receptors. Our in vivo findings support the hypothesis that painful distraction of the cervical facet capsule can induce local changes to the collagen fibers in that ligament that are not immediately recovered upon its unloading.

Both the fiber organization and structural mechanics studies suggest the lateral aspect of the rat facet capsular ligament is more prone to injury during tensile distraction. Fiber alignment significantly decreased in the lateral, but not the dorsal, aspect of the capsule after SV distraction (Figure 9). Likewise, partial failures occurred only in the lateral aspect and dorsolateral ridge during distraction. Despite these results, maximum principal strain measured in the structural mechanics study was located in the dorsal aspect for the majority of specimens (Table 5). Further, principal directions in the lateral aspect of the joint deviated from the direction of loading more than they did in the dorsal aspect. This suggests that principal strain alone may not be a sufficient outcome measure to understand the relationship between mechanical loading and physiologic outcomes. Advanced characterization of the capsule's mechanical properties, including a microstructural model of ligament tensile mechanical behavior, and a multi-metric approach to defining thresholds for nociception are likely needed to fully understand this relationship.

\section{CONCLUSIONS}

This study builds on previous investigations of the cervical facet capsule's mechanical responses which inferred tissue damage via measures of yield, ligament tears, and afferent activity. Subfailure loading paradigms that are associated with symptoms of persistent pain produced increases in joint laxity and decreased stiffness that imply potential tissue damage. Further, for these same displacements, ligament fiber organization was disrupted, suggesting damage to the ligament's extracellular matrix. These studies revealed an apparent disconnect between the regional distribution of strains measured at the capsules surface and the location of tissue tears and fiber disorganization. While subfailure strains have formed the basis of thresholds for developing pain in this joint, the findings of this study suggest such approaches may not be sufficient. An added level of complexity, integrating multiple mechanistic pathways, must be considered in determining relevant thresholds for physiologic dysfunction in this joint.

\section{ACKNOWLEDGMENTS}

We thank Dr. Louis Soslowsky and the Penn Center for Musculoskeletal Disorders for use of the polarized light microscopy equipment and analysis software. This work was funded by grant support from: the Southern Consortium for Injury Biomechanics/ NHTSA, the National Center for Injury Prevention and Control (R49CE000689), the Whitaker Foundation, and the Catharine D. Sharpe Foundation. This material is based upon work supported by the National Science Foundation under Grant No. 0547451.

\section{REFERENCES}

Aprill, C., and Bogduk, N. (1992) The prevalence of cervical zygapophyseal joint pain. A first approximation. Spine 17(7): 744-747.

Abdel-Aziz, Y.I., and Karara, H.M. (1971) Direct linear transformation from comparator coordinates into object space coordinates in close-range photogrammetry. Proceedings of the Symposium on Close-Range Photogrammetry, pp. 1-18. American Society of Photogrammetry, Falls Church, VA.

Barnsley, L., Lord, S., and Bogduk, N. (1993) Comparative local anaesthetic blocks in the diagnosis of cervical zygapophysial joint pain. Pain 1993: 99-106.

Barnsley, L., Lord, S., and Bogduk, N. (1994) Whiplash injury. Pain 58: 283-307.

Bogduk, N., and Yoganandan, N. (2001) Biomechanics of the cervical spine. Part 3: minor injuries. Clinical Biomechanics 16: 267-275.

Boorman, R.S., Norman, T., Matsen, F.A., and Clark, J.M. (2006) Using a freeze substitution fixation technique and histological crimp analysis for characterizing regions of strain in ligaments loaded in situ. Journal of Orthopaedic Research 24(4): 793-799.

Bruns, J., Kampen, J., Kahrs, J., and Plitz, W. (2000) Achilles tendon rupture: experimental results on spontaneous repair in a sheep model. Knee Surgery, Sports Traumatology, Arthroscopy 8(6): 364-369.

Cavanaugh, J.M., El-Bohy, A., Hardy, W.N., Getchell, T.V., Getchell, M.L., and King, A.I. (1989) Sensory innervation of soft tissues of the lumbar spine in the rat. Journal of Orthopaedic Research 7(3): 378-388. 
Cavanaugh, J.M., Ozaktay, A.C., Yamashita, H.T., and King, A.I. (1996) Lumbar facet pain: biomechanics, neuroanatomy, and neurophysiology. Journal of Biomechanics 29: 1117-1129.

Chen, C., Lu, Y., Cavanaugh, J.M., Kallakuri, S., and Patwardhan, A. (2005) Recording of neural activity from goat cervical facet joint capsule using custom-designed miniature electrodes. Spine 30(12): 1367-1372.

Chen, C., Lu, Y., Kallakuri, S., Patwardhan, A., and Cavanaugh, J.M. (2006) Distribution of A- $\delta$ and Cfiber receptors in the cervical facet joint capsule and their response to stretch. Journal of Bone and Joint Surgery 88-A(8):1807-1816.

Chen, L., Armstrong, C.W., and Raftopoulos, D.D. (1994) An investigation on the accuracy of threedimensional space reconstruction using the direct linear transformation technique. Journal of Biomechanics 27: 493-500.

Cusick, J.F., Pintar, F.A., and Yoganandan, N. (2001) Whiplash syndrome. Spine 26(11): 1252-1258.

Deng, B., Begeman, P.C., Yang, K.H., Tashman, S., and King, A.I. (2000) Kinematics of human cadaver cervical spine during low speed rear-end impacts. Stapp Car Crash Journal 44: 171-188.

Diamant, J., Keller, A., Baer, E., Litt, M., and Arridge, R.G. (1972) Collagen; ultrastructure and its relation to mechanical properties as a function of ageing. Proceedings of the Royal Society of London. Series B. Biological Sciences 180(60): 293-315.

Dickey, J.P., Hewlett, B.R., Duman, G.A., and Bednar, D.A. (1998) Measuring collagen fiber orientation: a two-dimensional quantitative macroscopic technique. Journal of Biomechanical Engineering 120:537-540.

Freeman, M.D., Croft, A.C., Rossignol, A.M., Weaver, D.S., and Reiser, M. (1999) A Review and methodologic critique of the literature refuting whiplash syndrome. Spine 24(1): 86-96.

Gargan, M.F., and Bannister, G.C. (1990) Long-term prognosis of soft-tissue injuries of the neck. Journal of Bone and Joint Surgery (British) 72(5): 901-903

Gathercole, L.J., and Keller, A. (1991) Crimp morphology in the fibre-forming collagens. Matrix 11:214-234.
Gimbel, J.A., Van Kleunen, J.P., Lake, S.P., Williams, G.R., and Soslowsky, L.J. (2007) The role of repair tension on tendon to bone healing in an animal model of chronic rotator cuff tears. Journal of Biomechanics 40: 561-568.

Gimbel, J.A., Van Kleunen, J.P., Mehta, S., Perry, S.M., Williams, G.R., and Soslowsky, L.J. (2004) Supraspinatus tendon organizational and mechanical properties in a chronic rotator cuff tear animal model. Journal of Biomechanics 37:739749.

Grauer, J.N., Panjabi, M.M., Cholewicki, J., Nibu, K., and Dvorak, J. (1997) Whiplash produces an Sshaped curvature of the neck with hyperextension at lower levels. Spine 22(21): 2489-2494.

Hatze, H. (1988) High-precision three-dimensional photogrammetric calibration and object space reconstruction using a modified DLT-approach. Journal of Biomechanics 21: 533-538.

Iatridis, J.C., MacLean, J.J., and Ryan, D.A. (2005) Mechanical damage to the intervertebral disc annulus fibrosus subjected to tensile loading. Journal of Biomechanics 38: 557-65.

Inami, S., Shiga, T., Tsujino, A., Yabuki, T., Okado, N., and Ochiai, N. (2001) Immunohistochemical demonstration of nerve fibers in the synovial fold of the human cervical facet joint. Journal of Orthopaedic Research 19(4): 593-596.

Ito, S., Ivancic, P.C., Panjabi, M.M., and Cunningham, B.W. (2004) Soft tissue injury threshold during simulated whiplash. Spine 29(9): 979-987.

Järvinen, T.A.H., Järvinen, T.L.N., Kannus, P., Józsa, L., and Järvinen, M. (2004) Collagen fibres of the spontaneously ruptured human tendons display decreased thickness and crimp angle. Journal of Orthopaedic Research 22(6): 1303-1309.

Junqueira, L.C., Bignolas, G., and Brentani, R.R. (1979) Picrosirius staining plus polarization microscopy, a specific method for collagen detection in tissue sections. Histochemical Journal 11: 447-455.

Kaneoka, K., Ono, K., Inami, S., and Hayashi, K. (1999) Motion analysis of cervical vertebrae during whiplash loading. Spine 24(8): 763-770.

Lee, K.E., Davis, M.B., Gupta, M.S., and Winkelstein, B.A. (2007) Contributions of the Capsular Ligament in Initiation and Maintenance of Mechanical Allodynia Following Facet Joint 
Distraction in a Rodent Model of Pain. Anesthesiology, Submitted.

Lee, K.E., Davis, M.B., Mejilla, R.M., and Winkelstein, B.A. (2004a) In vivo cervical facet capsule distraction: mechanical implications for whiplash \& neck pain. Stapp Car Crash Journal 48: 373-395.

Lee, K.E., Franklin, A.N., Davis, M.B., and Winkelstein, B.A. (2006) Tensile cervical facet capsule mechanics: Failure and subfailure responses in the rat. Journal of Biomechanics 39: 1256-1264.

Lee, K.E., Thinnes, J.H., Gokhin, D.S., and Winkelstein, B.A. (2004b) A novel rodent neck pain model of facet-mediated behavioral hypersensitivity: Implications for persistent pain and whiplash injury. Journal of Neuroscience Methods 137(2): 151-159.

Lord, S.M., Barnsley, L., Wallis, B.J., and Bogduk, B. (1996) Chronic cervical zygapophysial joint pain after whiplash. Spine 21(15): 1737-1745.

Lu, Y., Chen, C., Kallakuri, S., Patwardhan, A., and Cavanaugh, J.M. (2005a) Neural response of cervical facet joint capsule to stretch: a study of whiplash pain mechanism. Stapp Car Crash Journal 49: 49-65.

Lu, Y., Chen, C., Kallakuri, S., Patwardhan, A., and Cavanaugh, J.M. (2005b) Neurophysiological and biomechanical characterization of goat cervical facet joint capsules. Journal of Orthopaedic Research 23(4): 779-787.

Luan, F., Yang, K.H., Deng, B., Begeman, P.C., Tashman, S., and King, A.I. (2000) Qualitative analysis of neck kinematics during low-speed rearend impact. Clinical Biomechanics 15: 649-657.

Luo, P.F., Chao, Y.J., Sutton, M.A., and Peters III, W.H. (1993) Accurate measurement of threedimensional deformations in deformable and rigid bodies using computer vision. Experimental Mechanics 33: 123-132.

McLain, R.F. (1994) Mechanoreceptor endings in human cervical facet joints. Spine 19(5): 495-501.

McMahon, P.J., Dettling, J., Sandusky, M.D., Tibone, J.E., and Lee, T.Q. (1999) The anterior band of the inferior glenohumeral ligament. Journal of Bone and Joint Surgery (British) 81(3): 406-413.
Myklebust, J.B., Pintar, F., Yoganandan, N., Cusick, J., Maiman, D., Myers, T.J., and Sances Jr. A. (1988) Tensile Strength of Spinal Ligaments. Spine 13(5): 526-531.

Niven, H., Baer, E., and Hiltner, A. (1982) Organization of collagen fibers in rat tail tendon at the optical microscope level. Collagen and Related Research 2:131-142.

Ono, K., Kaneoka, K., Wittek, A., and Kajzer, J. (1997) Cervical injury mechanism based on the analysis of human cervical vertebral motion and head-neck-torso kinematics during low speed rear impacts. Stapp Car Crash Journal 41: 339-356.

Panjabi, M.M., Cholewicki, J., Nibu, K., Grauer, J.N., and Vahldiek, M. (1998) Capsular ligament stretches during in vitro whiplash simulations. Journal of Spinal Disorders 11: 227-232.

Panjabi, M.M., and Courtney T.W. (2001) Highspeed subfailure stretch of rabbit anterior cruciate ligament: changes in elastic, failure, and viscoelastic characteristics. Clinical Biomechanics 16: 334-340.

Panjabi, M.M., Moy, P., Oxland, T.R., and Cholewicki, J. (1999) Subfailure injury affects the relaxation behavior of rabbit ACL. Clinical Biomechanics 14: 24-31.

Panjabi, M.M., Yoldas, E., Oxland, T.R., and Crisco, J.J. (1996) Subfailure injury of the rabbit anterior cruciate ligament. Journal of Orthopaedic Research 14(2): 216-222.

Pearson, A.M., Ivancic, P.C., Ito, S., and Panjabi, M.M. (2004) Facet joint kinematics and injury mechanisms during simulated whiplash. Spine 29(4): 390-397.

Pollock, R.G., Wang, V.M., Bucchieri, J.S., Cohen, N.P., Huang, C.Y., Pawluk, R.J., Flatow, E.L., Bigliani, L.U., and Mow, V.C. (2000) Effects of repetitive subfailure strains on the mechanical behavior of the inferior glenohumeral ligament. Journal of Shoulder and Elbow Surgery 9: 427435.

Provenzano, P.P., Heisey, D., Hayashi, K., Lakes, R., and Vanderby Jr., R. (2002) Subfailure damage in ligament: a structural and cellular evaluation. Journal of Applied Physiology 92: 362-371.

Quinlan, K.P., Annest, J.L., Myers, B., Ryan, G., and Hill, H. (2004) Neck strains and sprains among motor vehicle occupants-United States, 2000. Accident Analysis and Prevention 36: 21-27. 
Quinn, K.P., and Winkelstein, B.A. (2007) Cervical facet capsular ligament yield defines the threshold for injury and persistent joint-mediated neck pain. Journal of Biomechanics 40: 2299-2306.

Radanov, B.P., Sturznegger, M., and Stefano, G.D. (1995) Long-term outcome after whiplash injury: a two-year follow-up considering features of injury mechanism and somatic, radiologic, and psychosocial factors. Medicine 74:281-297.

Siegmund, G.P., Myers, B.S., Davis, M.B., Bohnet, H.F., and Winkelstein, B.A. (2000) Human cervical motion segment flexibility and facet capsular ligament strain under combined posterior shear, extension and axial compression. Stapp Car Crash Journal 44: 159-170.

Siegmund, G.P., Myers, B.S., Davis, M.B., Bohnet, H.F., and Winkelstein, B.A. (2001) Mechanical evidence of cervical facet capsule injury during whiplash. Spine 26(19): 2095-2101.

Stemper, B.D., Yoganandan, N., and Pintar, F.A. (2005) Effects of abnormal posture on capsular ligament elongations in a computational model subjected to whiplash loading. Journal of Biomechanics 38: 1313-1323.

Sundararajan, S., Prasad, P., Demetropolous, C.K., Tashman, S., Begeman, P.C., Yang, K.H., and King, A.I. (2004) Effect of head-neck position on cervical facet stretch of post mortem human subjects during low speed rear end impacts. Stapp Car Crash Journal 48: 331-372.

Svensson, M.Y., Aldman, B., Bostrom, O., Davidsson, J., Hansson, H.A., Lovsund, P., Suneson, A., and Saljo, A. (1998) Transient pressure gradients in the pig spinal canal during experimental whiplash motion causing membrane dysfunction in spinal ganglion nerve cells. Orthopade 27(12): 820-826.

Thomopoulos, S., Williams, G.R., and Soslowsky, L.J. (2003) Tendon to bone healing: differences in biomechanical, structural, and compositional properties due to a range of activity levels. Journal of Biomechanical Engineering 125:106-113.

Uchiyama, E., Kitaoka, H.B., Luo, Z.P., Grande, J.P., Kura, H., and An, K.N. (2005) Pathomechanics of hallux valgus: biomechanical and immunohistochemical study. Foot \& Ankle International 26(9): 732-738.
Vilarta, R., and Vidal Bde, C. (1989) Anisotropic and biomechanical properties of tendons modified by exercise and denervation: aggregation and macromolecular order in collagen bundles. Matrix 9: 55-61.

Whittaker, P., and Canham, P.B. (1991) Demonstration of quantitative fabric analysis of tendon collagen using two-dimensional polarized light microscopy. Matrix 11:56-62.

Winkelstein, B.A., Nightingale, R.W., Richardson, W.J., and Myers, B.S. (1999) Cervical facet joint mechanics: its application to whiplash injury. Stapp Car Crash Journal 43: 243-252.

Winkelstein, B.A., Nightingale, R.W., Richardson, W.J., and Myers, B.S. (2000) The cervical facet capsule and its role in whiplash injury. Spine 25(10): 1238-1246.

Woltring, H.J. (1980) Planar control in mulit-camera calibration for 3-D gait studies. Journal of Biomechanics 13: 39-48.

Yeh, A.T., Choi, B., Nelson, J.S., and Tromberg, B.J. (2003) Reversible dissociation of collagen in tissues. The Journal of Investigative Dermatology 121(6): 1332-1335.

Yoganandan, N., Cusick, J.F., Pintar, F.A., and Rao, R.D. (2001) Whiplash injury determination with conventional spine imaging and cryomicrotomy. Spine 26(22): 2443-2448.

Yoganandan, N., Kumaresan, S., and Pintar, F. (2000) Geometric and mechanical properties of human cervical spine ligaments. Journal of Biomechanical Engineering 122: 623-629.

Yoganandan, N., and Pintar, F.A. (1997) Inertial loading of the human cervical spine. Journal of Biomechanical Engineering 119: 237-240.

Yoganandan, N., Ray, G., Pintar, F.A., Myklebust, J.B., and Sances Jr., A. (1989) Stiffness and strain energy criteria to evaluate the threshold of injury to an intervertebral joint. Journal of Biomechanics 22: 135-142.

Zimmermann M. (1983) Ethical guidelines for investigations of experimental pain in conscious animals. Pain 16:109-110. 